\title{
Durability and Shrinkage Characteristics of Self-Compacting Concretes Containing Recycled Coarse and/or Fine Aggregates
}

\author{
Mehmet Gesoglu, ${ }^{1}$ Erhan Güneyisi, ${ }^{1}$ Hatice Öznur Öz, \\ Mehmet Taner Yasemin, ${ }^{1}$ and Ihsan Taha ${ }^{3}$ \\ ${ }^{1}$ Department of Civil Engineering, Gaziantep University, 27310 Gaziantep, Turkey \\ ${ }^{2}$ Department of Civil Engineering, Nigde University, 51240 Nigde, Turkey \\ ${ }^{3}$ Department of Civil Engineering, University of Technology, Baghdad, Iraq \\ Correspondence should be addressed to Hatice Öznur Öz; oznuroz@nigde.edu.tr
}

Received 6 May 2015; Accepted 16 July 2015

Academic Editor: Rui Vilar

Copyright (C) 2015 Mehmet Gesoglu et al. This is an open access article distributed under the Creative Commons Attribution License, which permits unrestricted use, distribution, and reproduction in any medium, provided the original work is properly cited.

\begin{abstract}
This paper addresses durability and shrinkage performance of the self-compacting concretes (SCCs) in which natural coarse aggregate (NCA) and/or natural fine aggregate (NFA) were replaced by recycled coarse aggregate (RCA) and/or recycled fine aggregate (RFA), respectively. A total of 16 SCCs were produced and classified into four series, each of which included four mixes designed with two water to binder (w/b) ratios of 0.3 and 0.43 and two silica fume replacement levels of 0 and $10 \%$. Durability properties of SCCs were tested for rapid chloride penetration, water sorptivity, gas permeability, and water permeability at 56 days. Also, drying shrinkage accompanied by the water loss and restrained shrinkage of SCCs were monitored over 56 days of drying period. Test results revealed that incorporating recycled coarse and/or fine aggregates aggravated the durability properties of SCCs tested in this study. The drying shrinkage and restrained shrinkage cracking of recycled aggregate (RA) concretes had significantly poorer performance than natural aggregate (NA) concretes. The time of cracking greatly prolonged as the RAs were used along with the increase in water/binder ratio.
\end{abstract}

\section{Introduction}

Self-compacting concrete (SCC) is characterized by uniform strength, low void spaces, very high levels of homogeneity, finishing, and durability of structure [1]. The unique characteristic of SCC is a rapid rate of concrete placement. Compaction of this concrete is accomplished in all the parts of the form, including the hardly accessible parts, with no additional external force, except the gravity that is a result of the concrete self-weight $[2,3]$. Such properties can be achieved by the addition of chemical additives to the concrete, such as superplastificators, most frequently combined with the new type of additives for modification of viscosity, and/or through the application of a certain amount of fine mineral additive powder [4]. Properties of SCC depend on the type and amount of the additive [2].

As aggregates occupy $60-70 \%$ of volume in SCC, they have an important role in both mechanical and durability properties of SCCs. The aggregates also have a significant effect on the cost of SCC. In addition, there is a critical shortage of natural aggregate (NA) in many regions of the world due to construction growth in developing countries as well as reconstruction in sophisticated countries $[5,6]$. Recently, a comprehensive tendency to maintain the environment by reducing the consumption of nonrenewable natural resources like concrete had been spread. Recycling concrete used as recycled aggregate (RA) not only reduces the use of virgin aggregate but also minimizes the landfills. In general, as the quality of RA is inferior to those of NAs, it is expected that RAs cause the adverse effect on the interfacial bond between RAs surface and new cement paste $[7,8]$. Furthermore, the density of RAs is lower than that of NAs and RAs have a greater water absorption and higher porosity value compared to NAs. This is because not only the RAs contain the original aggregate, but also hydrated cement paste adhered to the surface of this aggregate which in turn makes RAs more porous 
than NAs. Hansen [9] reported that the residual mortar in RAs resulted in a decrease in the specific gravity and an increase in both water absorption and Los Angeles abrasion loss. The most notable of these differences was the significant increase in water absorption of RAs as compared to that of NAs. The water absorption capacity of RAs affects the amount of cement paste adhering to the surface of the aggregate particles. Therefore, the characteristics of RAs should be taken into consideration for the performance required in fresh and hardened state of concrete [3].

Many researchers have examined the effect of RA properties on the concrete in hardened state. Katz [10] stated that the properties of the concrete made with RAs were inferior to those of concrete made with NAs. According to Dhir et al. [11], the strength reduction due to utilizing RAs can be mitigated by reducing the water to cement ratio of the mixture. However, the developing interest in the usage of RAs increases concern over the long-term performance of concrete related to shrinkage. The drying and total shrinkage strains of concrete with RAs are, respectively, 2.56 and 1.26 times greater than those of normal concrete [12]. The increased shrinkage of concrete incorporating RA may be the result of the attached mortar and cementing paste in the recycled aggregate grains [13]. However, it was reported that the increase in drying shrinkage of RA concrete is imputable to the old mortar adhering to the natural aggregate and also due to the content, interconnection, and distribution of pore size [14]. Nevertheless, attenuation of the increases in drying shrinkage of RA concrete may be feasible through the suitable use of shrinkage-reduction agents [15].

Silica fume (SF) can be utilized as material for supplementary cementations to increase the strength and durability of concrete. The known effect of SF is the improvement of the bond between the paste and aggregate $[16,17]$. Therefore it has been used as a replacement material in the production of SCCs. Al-Khaja [17] stated that the shrinkage of plain concrete was considerably or moderately reduced with the incorporation of SF. Furthermore, Li and Yao [18] reported that ultrafine ground granulated blast furnace slag (GGBFS) enhanced and strengthened the structure of concrete and decreased the deformation caused by drying shrinkage.

So far much work has been focused on the fresh and mechanical properties of SCCs, neglecting durability properties like permeability and shrinkage. Therefore, the main focus of this study is to assess the influence of RAs on the some durability properties of SCCs made with recycled fine (RFA) and/or recycled coarse aggregate (RCA) to provide further information on the current application requirements. The permeability was examined through rapid chloride penetration (RCPT), water sorptivity, and water permeability as well as gas permeability tests at the age of 56 days. Also, drying shrinkage, accompanied weight loss, and restrained shrinkage of SCCs were monitored over 56 days.

\section{Experimental Program}

2.1. Cement, Slag, Silica Fume, and Superplasticizer. In this study, ordinary Portland cement (CEM I 42.5 R), conforming to the TS EN 197 [19] with a specific gravity of $3.15 \mathrm{~g} / \mathrm{cm}^{3}$ and
TABLE 1: Properties of cement, ground granulated blast furnace slag, and silica fume.

\begin{tabular}{lccc}
\hline Chemical analysis (\%) & Cement & GGBFS* & SF $^{* *}$ \\
\hline $\mathrm{CaO}$ & 62.12 & 34.12 & 0.45 \\
$\mathrm{SiO}_{2}$ & 19.69 & 36.41 & 90.36 \\
$\mathrm{Al}_{2} \mathrm{O}_{3}$ & 5.16 & 10.39 & 0.71 \\
$\mathrm{Fe}_{2} \mathrm{O}_{3}$ & 2.88 & 0.69 & 1.31 \\
$\mathrm{MgO}$ & 1.17 & 10.26 & - \\
$\mathrm{SO}_{3}$ & 2.63 & - & 0.416 \\
$\mathrm{~K}_{2} \mathrm{O}$ & - & 0.97 & 1.52 \\
$\mathrm{Na}_{2} \mathrm{O}$ & 0.17 & 0.35 & 0.45 \\
$\mathrm{Cr}_{2} \mathrm{O}_{3}$ & 0.88 & - & - \\
Loss of ignition & 0.87 & 1.64 & 3.1 \\
Specific gravity & 3.15 & 2.79 & 2.20 \\
Specific surface area $\left(\mathrm{m}^{2} / \mathrm{kg}\right)$ & 394 & 418 & 21080 \\
\hline
\end{tabular}

${ }^{*}$ GGBFS: ground granulated blast furnace slag.

${ }^{* *}$ SF: silica fume.

TABLE 2: Physical properties of NA and RA.

\begin{tabular}{lcccc}
\hline \multirow{2}{*}{ Sieve size $(\mathrm{mm})$} & \multicolumn{2}{c}{$\mathrm{NA}$} & \multicolumn{2}{c}{$\mathrm{RA}$} \\
\hline 16 & $\mathrm{NFA}^{*}$ & $\mathrm{NCA}^{*}$ & $\mathrm{RFA}^{*}$ & $\mathrm{RCA}^{*}$ \\
8 & 100 & 100 & 100 & 100 \\
4 & 100 & 41.4 & 100 & 38.2 \\
2 & 100 & 0 & 97.7 & 0 \\
1 & 56.8 & 0 & 65.9 & 0 \\
0.5 & 35.0 & 0 & 42.3 & 0 \\
0.25 & 22.7 & 0 & 26.3 & 0 \\
\hline Fineness modulus & 3.69 & 5.58 & 3.50 & 5.62 \\
Specific gravity & 2.42 & 2.72 & 2.11 & 2.37 \\
\hline
\end{tabular}

${ }^{*}$ NCA: natural coarse aggregate.

${ }^{*} \mathrm{NFA}$ : natural fine aggregate.

${ }^{*}$ RCA: recycled coarse aggregate.

${ }^{*}$ RFA: recycled fine aggregate.

Blaine fineness of $394 \mathrm{~m}^{2} / \mathrm{kg}$, was used in all SCC mixes. A ground granulated blast furnace slag (GGBFS) and a commercial-grade silica fume (SF) were utilized as cement replacement materials. Chemical and physical properties of the cement, GGBFS, and SF are given in Table 1. A High Range Water Reducing Admixture (HRWRA) with a specific gravity of 1.07 was used to achieve the target workability.

\subsection{Aggregates}

2.2.1. Natural Aggregates (NAs). Natural fine aggregates (NFAs) and natural coarse aggregates (NCAs) were replaced by recycled fine aggregates (RFAs) and recycled coarse aggregates (RCAs), respectively, to produce 16 different SCC mixtures. NFA was crushed sand with a specific gravity of 2.42 and a fineness modulus of 2.38. NCA had a maximum size of $16 \mathrm{~mm}$, a specific gravity of 2.73 , and a fineness modulus of 5.61. Sieve analysis and physical properties of NAs are shown in Table 2. Mix proportions of the aggregates conformed to the grading curve specified in TS 706 [20]. 


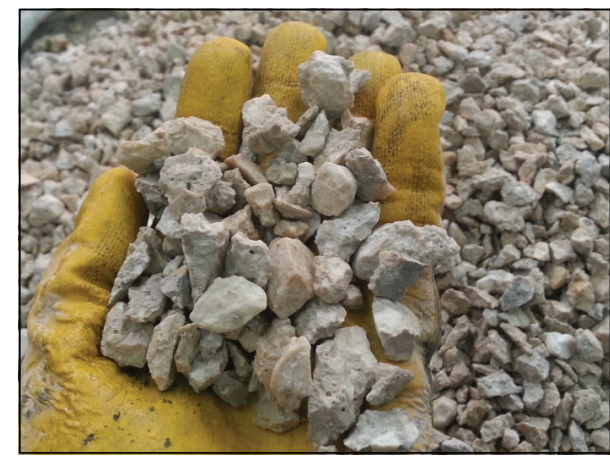

(a)

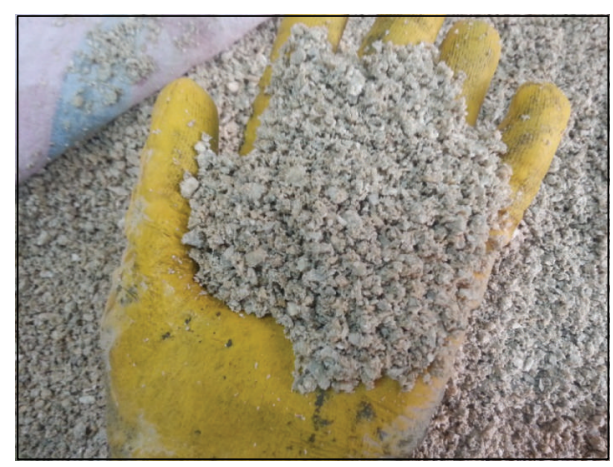

(b)

FIgURE 1: RAs: (a) RCAs and (b) RFAs as SSD condition.

2.2.2. Recycle Aggregates (RAs). RAs were manufactured in two stages; the first stage included the preparation of a conventional concrete with a compressive strength of almost $20 \mathrm{MPa}$. In the second stage, the ordinary concrete was crushed and sifted into fine and coarse fractions. Sieve analysis and physical properties of RAs determined as per ASTM C127 [21] are summarized in Table 2. Recycled fine aggregate (RFA) used in the present study had a size of $0.25-4 \mathrm{~mm}$, a specific gravity of 2.11, and a 24 -hour absorption of $17.9 \%$. On the other hand, recycled coarse aggregate (RCA) had a size of $4-16 \mathrm{~mm}$, a specific gravity of 2.37 , and a 24 -hour absorption of $7.39 \%$. Both RFA and RCA were used in saturated surface dry (SSD) condition to prevent early slump loss of SCCs (Figure 1).

2.3. Mixture Proportioning and Casting. Totally, sixteen concrete mixes were designed and produced in a pan-type mixer with a 20 L capacity according to ASTM C192 [22]. The mixes were subdivided into four series; SCC mixes in Series I were prepared with $100 \%$ NA for both coarse and fine aggregates while series II mixes included the concretes with 100\% RCA and $100 \%$ NFA. Series III contained $100 \%$ NCA and $100 \%$ RFA. Finally, Series IV concretes were incorporated with $100 \%$ RA for both coarse and fine aggregates. Each series consisted of 4 mixes; the first and second mixes were characterized by a binder content of $570 \mathrm{~kg} / \mathrm{m}^{3}$ and a w/b ratio of 0.3 , while the third and fourth mixes were prepared with a $480 \mathrm{~kg} / \mathrm{m}^{3}$ binder content and a $0.43 \mathrm{w} / \mathrm{b}$ ratio. In the second and fourth mixes of each series $10 \%$ of binder was replaced by silica fume while all of the mixes were incorporated with $25 \%$ GGBFS of total binder content by weight. Varying amount of HRWRA was used to provide the desired workability. In this paper, the mixes were designated in accordance with the mixture composition. For example, 0.3RCA0RFA0SF10 indicates that SCC is designed with a w/b of 0.3 ; the levels of RCA, RFA, and silica fume were 0,0 , and $10 \%$, respectively.

Considering the high water absorption of RAs, they were immersed beforehand in water for $30 \mathrm{~min}$ to ensure the saturated surface dry (SSD) condition $[1,2,23]$. Concrete casting sequence started with mixing RA in SSD with the binder for $60 \mathrm{~s}$ and was followed by incorporating NCA and/or NFA in the mixer. After homogenizing of the aggregates and the binder for $30 \mathrm{~s}$, the mix water containing HRWRA was added to two parts to avoid segregation, and the concrete was mixed for $3 \mathrm{~min}$ and then left for $2 \mathrm{~min}$ rest. Finally, the concrete was mixed for an additional 2 min to complete the mixing sequence. The slump flow diameter of SCCs was designed to be in the range of $680 \pm 30 \mathrm{~mm}$ to comply with EFNARC guidelines [4]. In order to achieve this target workability, trial batches were produced for each mixture by using HRWRA at varying amounts until the desired slump flow diameter has been obtained. Details of the SCC mixtures in addition to their 56-day compressive and splitting tensile strengths are given in Table 3.

SCCs were designed with compressive strengths in the range of 66.63-81.40, 55.38-70.39, 48.69-64.61, and 46.04$57.41 \mathrm{MPa}$ for Series I, II, III, and IV, respectively. As shown in Table 3, the use of RCAs, RFAs, and RCAs + RFAs decreased the compressive strength of the corresponding reference concretes by $11.8-16.9,15.8-26.9$, and $27.0-30.9 \%$, respectively. These results confirmed that the Series IV concrete, which was made with RCAs and RFAs, showed the lowest compressive strength values. The reduction in strength due to the incorporation of RAs may be due to the poor quality of the adhered mortar to RAs which has experienced the crushing process and consequently created weak areas in the concrete as well as the weak interfacial transition zone (ITZ) $[6,24]$. As seen in Table 3, the splitting tensile strength diminished due to the presence of RCAs and/or RFAs in SCCs. When the three series of SCCs were considered, it was found that the best strengths were observed for mixes in Series II where the NCAs were replaced by RCAs. The mixes containing $100 \%$ RAs exhibited the lowest splitting tensile strength among all the concrete mixtures. The SCCs in Series II, III, and IV showed a reduction in splitting tensile strength of 7.4$17.6 \%, 19.5-27.7 \%$, and $29.1-37.1 \%$, respectively, as compared to the corresponding control mixes in Series I. The old cement mortar attached to RAs is the main reason that weakens the properties of SCC. Therefore, the low-quality RA governs the strength reduction due to the weaker contact at the interfacial zone between the cement mortar and RAs. It is accepted that the usage of RAs rather than NAs reduces the splitting tensile of SCCs $[8,25]$. 


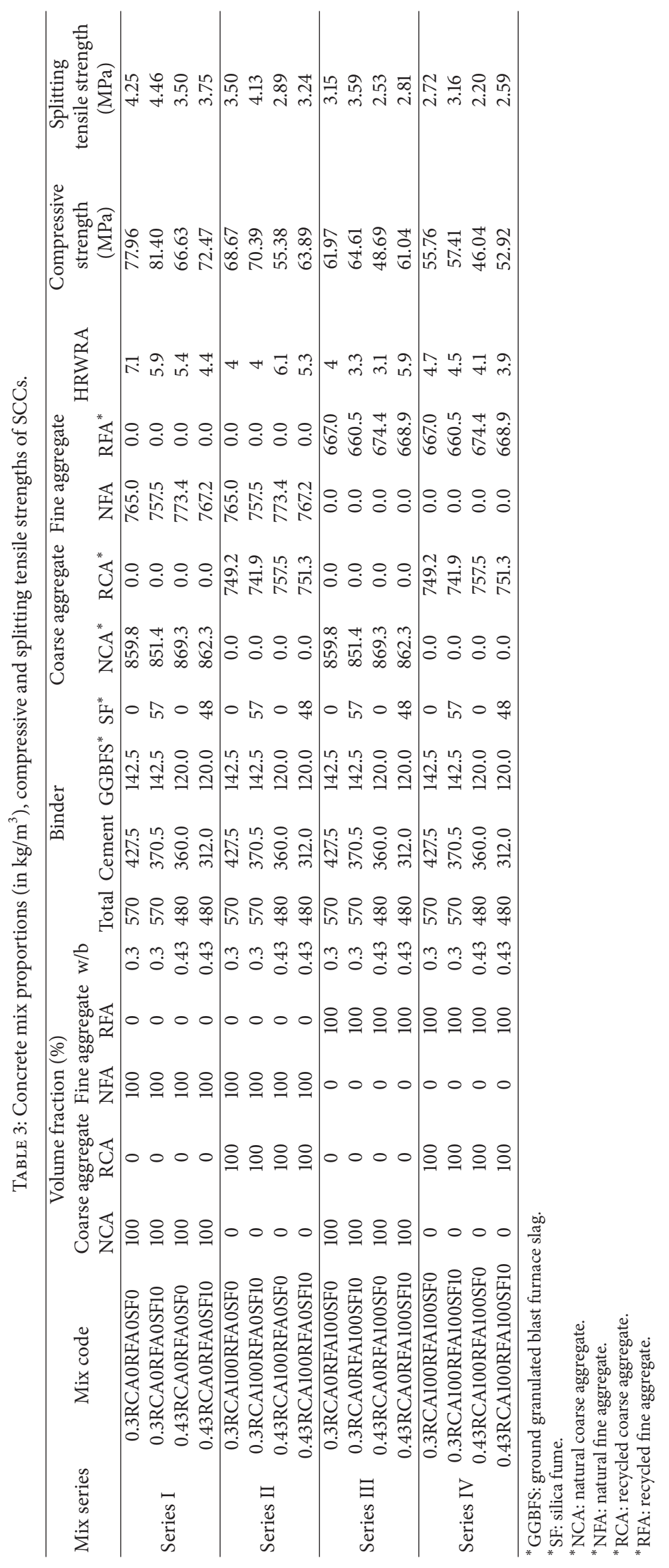




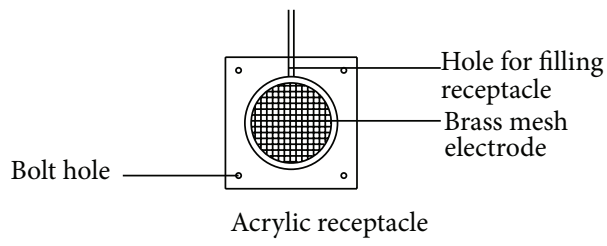

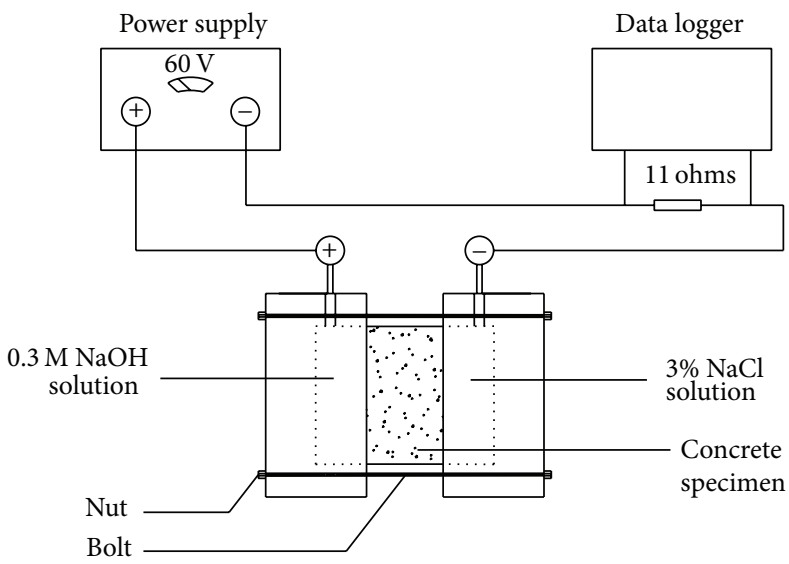

(a)

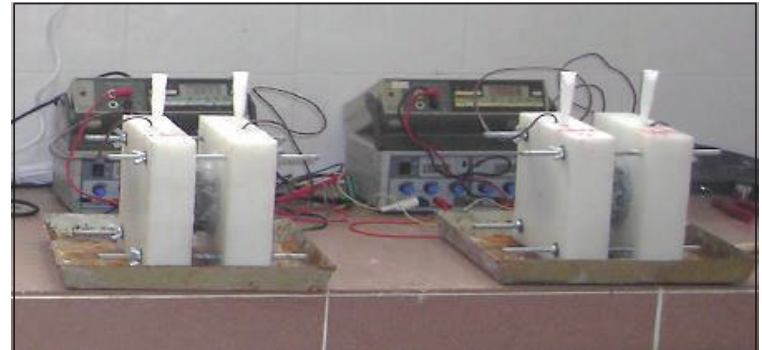

(b)

FIGURE 2: RCPT test setup: (a) schematic presentation of the test setup for RCPT and (b) photographic view of the RCPT test setup.

TABLE 4: Chloride ion penetrability based on charge passed according to ASTM C1202 [26].

\begin{tabular}{lc}
\hline Charge passed $Q$ & Chloride ion penetrability \\
\hline$>4000$ & High \\
$2000-4000$ & Moderate \\
$1000-2000$ & Low \\
$100-1000$ & Very low \\
$<100$ & Negligible \\
\hline
\end{tabular}

\subsection{Test Procedures}

2.4.1. Rapid Chloride Permeability Test (RCPT). To assess the chloride penetrability of concrete mixture presented in this study, a very popular and well-known experimental procedure was adopted. The rapid chloride permeability test (RCPT) is a standardized ASTM test that exists for 24 years [26]. The experiment assesses concrete's ability to resist chloride intervention. In fact, it measures the electrical conductivity or resistance of a concrete disc specimen for a period of $6 \mathrm{~h}$. It is assumed that the resistivity is directly related to the pore network or concrete permeability, although some researchers claim that such relation is not perfect [27]. The resistivity is measured in terms of the total electric charge (measured in coulombs, C) passed through the specimens, and these measurements are used for the classification of mixtures as shown in Table 4.

Figure 2 represents the schematic presentation and photographic view of the test setup for RCPT, respectively. The test was carried out according to ASTM C1202 recommendations [26]. The chloride ion permeability of the concretes was measured at the age of 56 days; two specimens were tested together for each mixture. For this purpose, three $50 \mathrm{~mm}$ thick disc samples were cut from the midsection of each specimen cylinder. Then, the discs were allowed to surface dry in air. In order to prevent evaporation of water from the saturated specimen, a rapid setting coating was applied onto the lateral surface of the specimens prior to a vacuum-saturation procedure for 2 hrs. Finally, the specimens were immersed in water in the curing room at $20^{\circ} \mathrm{C}$ and $50 \%$ relative humidity for $18 \pm 2 \mathrm{~h}$. Later, the disc specimens were transferred to a test cell in which one face of the specimen was subjected to a $0.30 \mathrm{~N} \mathrm{NaOH}$ solution and the other face was subjected to a $3 \% \mathrm{NaCl}$ solution (Figures 2 (a) and 2(b)). A direct voltage of $60.0 \pm 0.1 \mathrm{~V}$ was applied across the faces. Due to this applied voltage the chloride ions in the $\mathrm{NaCl}$ solution, being negatively charged, were attracted by the opposite positive electrode $(+)$ and they penetrated through the pores of saturated concrete. The data was measured at every $30 \mathrm{~min}$ to record the current passing through the specimens over a $6 \mathrm{~h}$ period. After completing the test, current (in amperes) versus time (in seconds) were plotted for each concrete and the area underneath the curve was integrated to obtain the charge passed (in coulombs).

2.4.2. Water Sorptivity Test. The sorptivity test measures the rate at which water is drawn into the pores of concrete. For this test, three specimens having a dimension of $100 \mathrm{~mm}$ in diameter and $50 \mathrm{~mm}$ in length cut from the $\varnothing 100 \times 200 \mathrm{~mm}$ cylinders were prepared. Before starting the test, the specimens were dried in an oven at about $105 \pm 5^{\circ} \mathrm{C}$ until achieving a constant mass and then allowed to cool to the ambient temperature in a sealed container. Afterwards, the sides of 


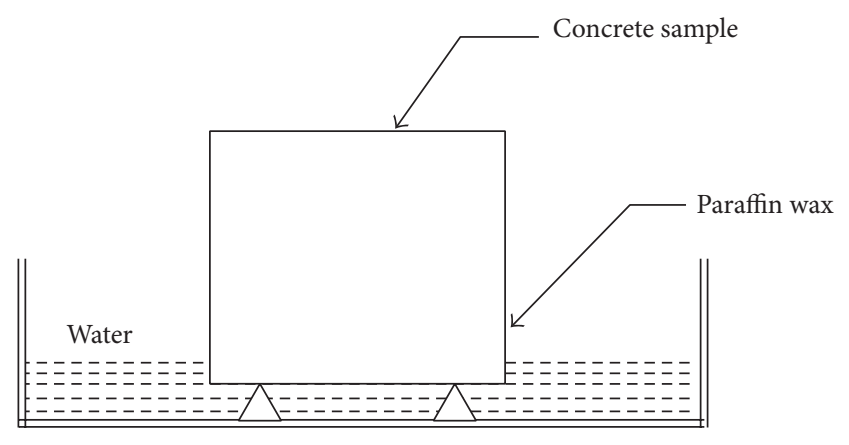

FIGURE 3: Details of water sorptivity measurement.

the specimens were coated by paraffin as shown in Figure 3. The water sorptivity test was conducted by placing the specimens on glass rods in a tray such that their bottom surface as much as to a height of $5 \mathrm{~mm}$ is in contact with water. This procedure was considered to allow free water movement through the surface of concrete. The total surface area of water within the tray should not be less than 10 times that of the specimen cross-sectional area. The specimens were removed from the tray and weighed at different time intervals up to $1 \mathrm{~h}$ to evaluate mass gain. The volume of water uptake from the concrete per unit cross-sectional area with time was calculated. For each test, the measurements were obtained from three specimens and the average values were reported. The test was conducted at the age of 56 days. Sorptivity was evaluated from the relation below:

$$
I=S^{\prime} \sqrt{ } t
$$

where $S^{\prime}$ is sorptivity $\left(\mathrm{mm} / \mathrm{min}^{1 / 2}\right)$ and $I$ is cumulative infiltration $(\mathrm{mm})$ at time $t(\mathrm{~min})$.

2.4.3. Gas Permeability Test. The CEMBUREAU method recommended by RILEM TC 116-PCD [28] was used for investigating the gas permeability coefficients of SCCs mixtures. Photos of test apparatus and the schematic layout as well as the details of the testing cell are shown in Figures 4(a), 4(b), and $4(\mathrm{c})$. The gas permeability of the concrete samples was measured on $50 \mathrm{~mm}$ height and $150 \mathrm{~mm}$ diameter concrete disk specimens cut from the midportion of $\Phi 150 \times 300 \mathrm{~mm}$ cylinder. Oxygen gas was used as the permeating medium. Differential pressures varying from 150 to $500 \mathrm{kPa}$ were applied to the specimens in pressure cells which were sealed by a tightly fitting rubber pressuring under high pressure against the curved surface. Prior to the gas permeability test, oven drying process was processed. When the curing period of 56 days was ended, the specimens would be dried at $105 \pm$ $5^{\circ} \mathrm{C}$ in oven to make sure that each specimen weight change was less than $1 \%$. Then, they were kept in a sealed box till the test began. Three specimens for each concrete mixture were tested at the age of 56 days and the average of them was reported as a test result.

For each differential pressure Hagen-Poiseuille relationship for laminar flow of a compressible fluid through a porous medium with small capillaries under steady-state condition was used to determine the apparent gas permeability coefficient $K$, which can be calculated using the modified Darcy equation:

$$
K=\frac{2 P_{2} Q L \mu}{A\left(P_{1}^{2}-P_{2}^{2}\right)},
$$

where $K$ is the gas permeability coefficient $\left(\mathrm{m}^{2}\right), P_{1}$ is the inlet gas pressure $\left(\mathrm{N} / \mathrm{m}^{2}\right), P_{2}$ is the outlet gas pressure $\left(\mathrm{N} / \mathrm{m}^{2}\right), A$ is the cross-sectional area of the sample $\left(\mathrm{m}^{2}\right), L$ is the height of sample $(\mathrm{m}), \mu$ is the viscosity of oxygen $\left(2.02 \times 10^{-5} \mathrm{Ns} / \mathrm{m}^{2}\right)$, and $Q$ is the rate of flow of air bubble $\left(\mathrm{m}^{3} / \mathrm{s}\right)$.

2.4.4. Water Permeability Test. Water permeability of SCCs mixtures was conducted according to TS EN 12390-8 [29]. For this, a $500 \pm 50 \mathrm{kPa}$ downward pressure was applied on the bottom side of the specimens for $72 \mathrm{~h}$. After that, the test specimens were split in the middle and the greatest penetration depth of water was evaluated in $\mathrm{mm}$. In order to characterize the concrete resistance to the chemical attack, water should not penetrate to a depth of more than $50 \mathrm{~mm}$ in concrete likely to come in contact with slightly aggressive media and not more than $30 \mathrm{~mm}$ if concrete is likely to come in contact with aggressive media. Water permeability test equipment photo is given in Figure 5. The results presented herein are the average of three concrete specimens.

2.4.5. Drying Shrinkage and Weight Loss. In order to observe the drying shrinkage and weight loss of the SCCs, three $70 \times$ $70 \times 280 \mathrm{~mm}$ prisms according to ASTM C157 [30] were used as shown in Figure 6. As soon as the prisms are demoulded, the gage length was fixed on each specimen by the means of the glued pins on the face of prisms. The length change was measured via a dial gage extensometer with $200 \mathrm{~mm}$ gage length and 0.002 strain for measuring. Measurements were implemented for the first 3 weeks as every $24 \mathrm{~h}$ and then 3 times a week. Meanwhile, measurements of weight loss were operated on the identical prism, too. After the gage length was fixed on each specimen via the glued pins on the face of prisms, its initial weight was recorded to monitor the weight loss during drying period. Then, the prisms specimens were subject to drying at $23 \pm 2^{\circ} \mathrm{C}$ and $50 \pm 5 \%$ relative humidity for about 56 days. The test results for each property were evaluated by averaging the measurement of three prism specimens.

2.4.6. Restrained Shrinkage Cracking. In this study, the ringshaped specimens were utilized in order to determine the shrinkage stimulated cracking of SCCs. With regard to drying and restrained shrinkage test immediately after casting, specimens were cured for $24 \mathrm{hr}$ in a cabinet having $100 \%$ relative humidity and temperature of $20^{\circ} \mathrm{C}$. Following this curing period, as soon as the outer mold of the ring specimen had been removed, the top surface of the concrete ring was covered via a silicone rubber, so that drying would be permitted only by the outer circumferential surface (Figures $7(\mathrm{a})$ and $7(\mathrm{~b}))$. Measurements were taken in the casting room at $23 \pm 2^{\circ} \mathrm{C}$ and $50 \pm 5 \%$ relative humidity. To measure the crack widths on ring specimens, a special microscope setup was used [31,32]. The crack widths reported herein were 


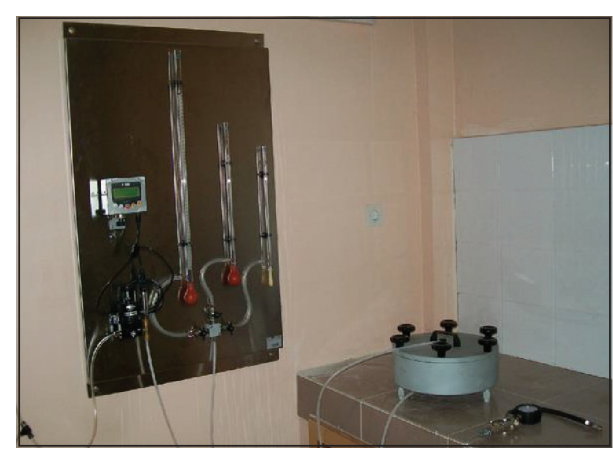

(a)

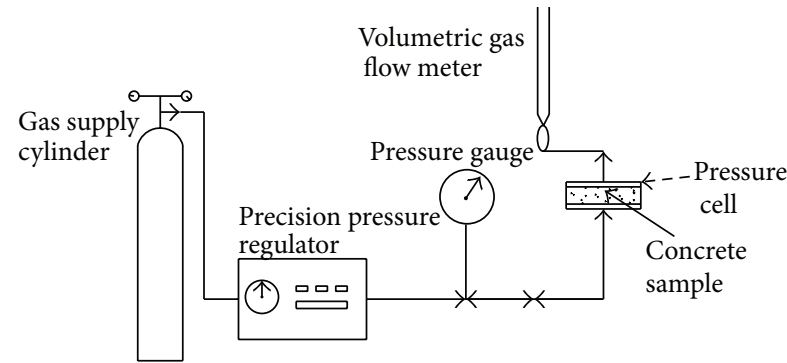

(b)

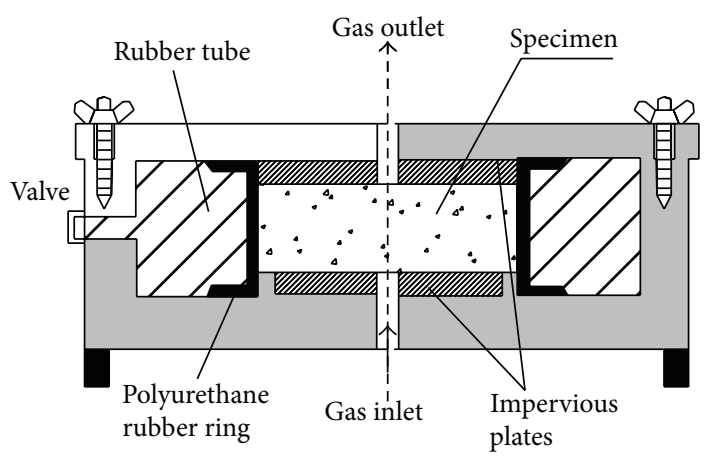

(c)

FIGURE 4: Gas permeability setup: (a) photographic view of the gas permeability test setup, (b) schematic presentation of the gas permeability test setup, and (c) schematic presentation of the pressure cell and test specimen.

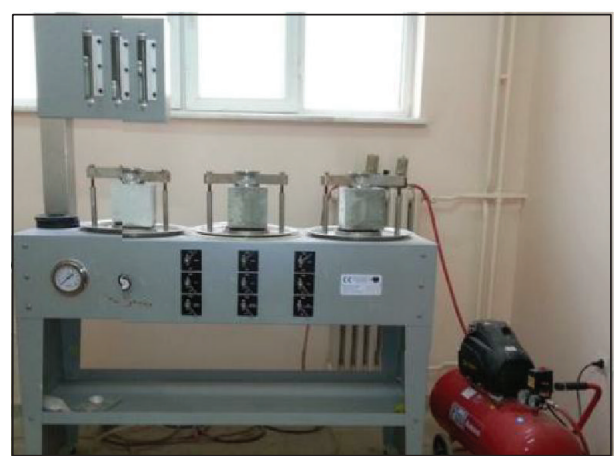

FIGURE 5: Water permeability test setup.

the average of three measurements: one at the center of the ring and the other two at the centers of the top and bottom halves of the ring. The surface of the specimens was examined for new cracks, and the measurement of the existing cracks widths was performed every $24 \mathrm{~h}$ during the first seven days after cracking and then every $48 \mathrm{~h}$. Restrained crack widths given here are the average of two ring specimens.

\section{Results and Discussion}

3.1. Rapid Chloride Permeability. Rapid Chloride Penetration Test (RCPT) test is done to monitor the diffusion characteristics of chloride in concrete. Diffusion is defined as the process by which liquid, gas, or ions move through a porous material under the action of a gradient. It may occur in partially-or fully-saturated concrete and is an important transport mechanism for most concrete structures that are exposed to salts [33]. According to the chloride ion penetrability as specified in ASTM C1202 [26], the total charge passed through SCCs is given in Table 5 and graphically presented in Figure 8. As shown in Figure 8, the lowest chloride ion permeability was achieved for the mixture 0.3 RCA0RFA0SF10, with a w/b of 0.3 and $10 \%$ SF. While the entire control mixes in Series I recorded penetration rates ranging from 308.7 to 685.44 coulombs, the mixes with $100 \%$ RAs in Series IV experienced the highest rates which varied between 1983 and 3528 coulombs. In the same way, the utilization of RCAs rather than NCAs and RFAs instead of NFAs resulted in an increase in the chloride penetration of about 2.3-3.4 and 2.6-3.3 times, respectively, higher than that for control mixes. RAs affected adversely the chloride ion permeability of the SCCs due to the increased pore size in the paste and also in the ITZ. The high water absorption of RAs reduced the quality of ITZ, which in turn increased the ingress of chloride ions with respect to Series II, III, and IV mixes. Furthermore, the increase in chloride ion penetration was mostly credited to the higher porosity of RAs; the adhered cement paste made the RCA porous and thus increased the overall permeable voids of concrete. Zhang et al. [34] confirmed the direct relationship between water permeability and chloride ion penetration. Also, Kanellopoulos et al. [27] showed that the replacement of natural aggregates 


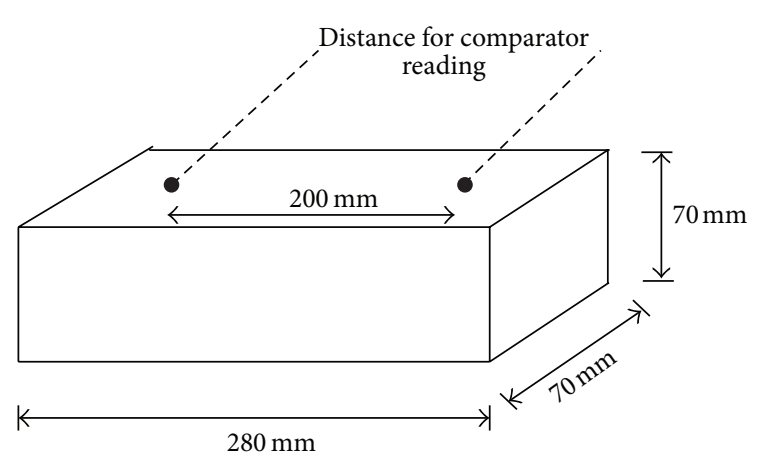

(a)

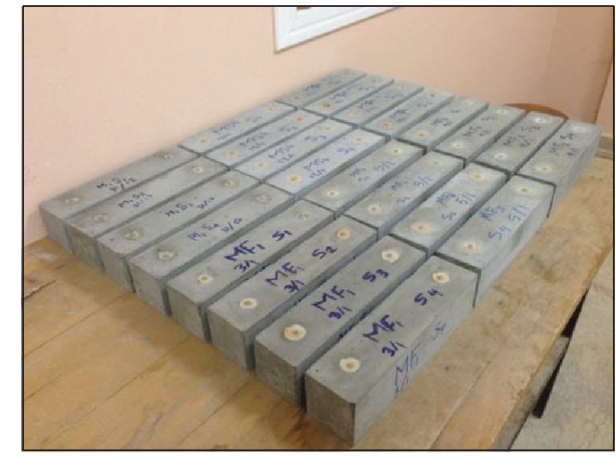

(b)

FIgURE 6: Free shrinkage test: (a) free shrinkage test setup and (b) test specimens.

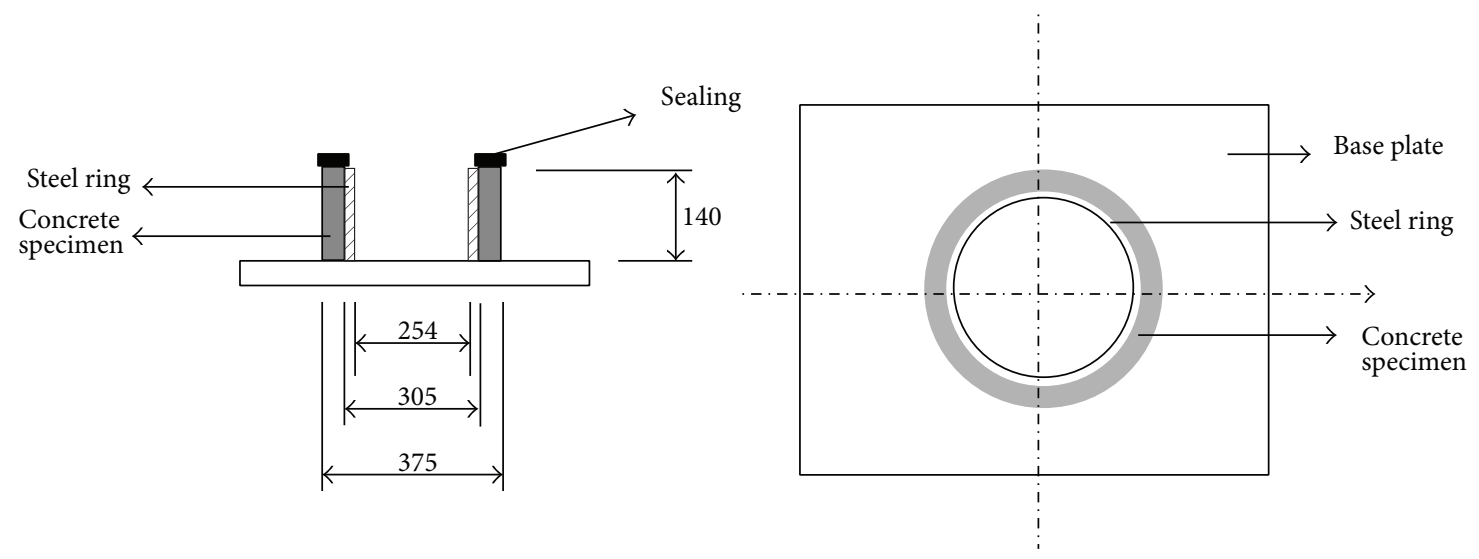

(a)
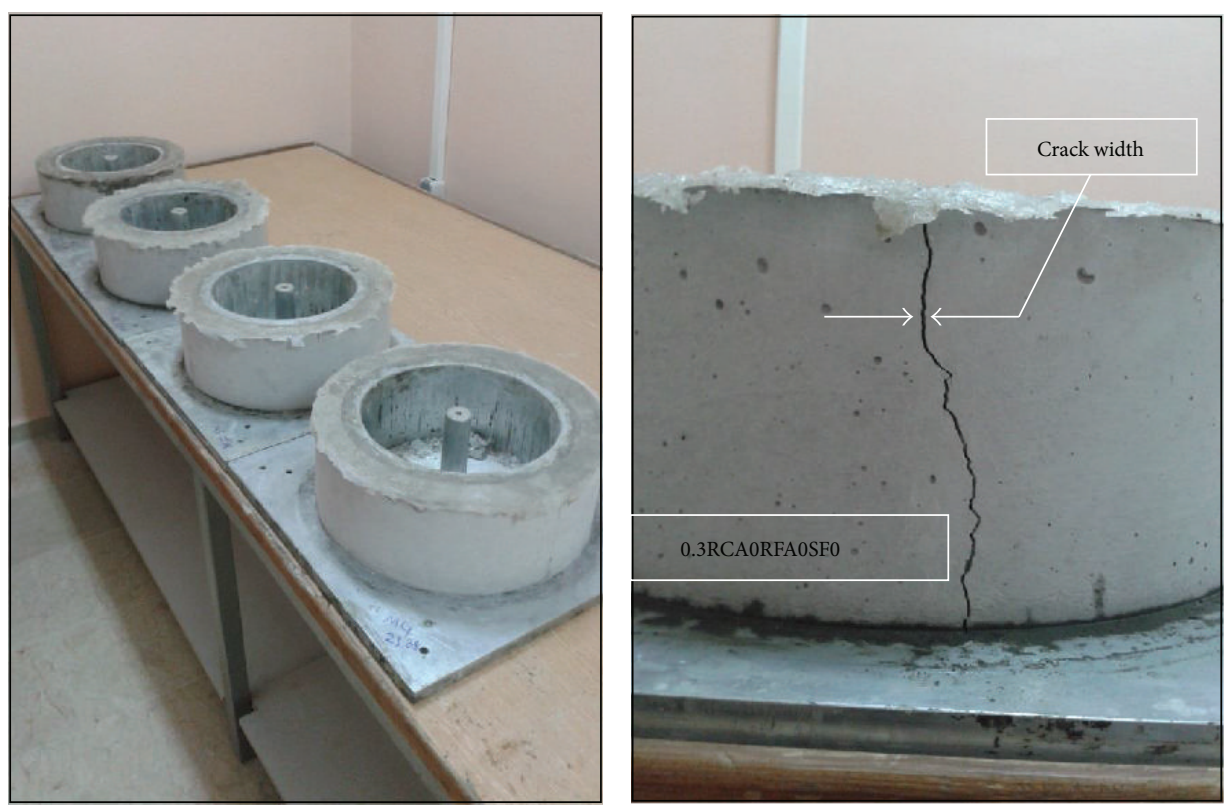

(b)

FIGURE 7: Restrained shrinkage cracking test: (a) dimensions of a restrained shrinkage ring specimen (in mm) and (b) photographic view of a cracked ring specimen in control mix (0.3RCA0RFA0SF0). 


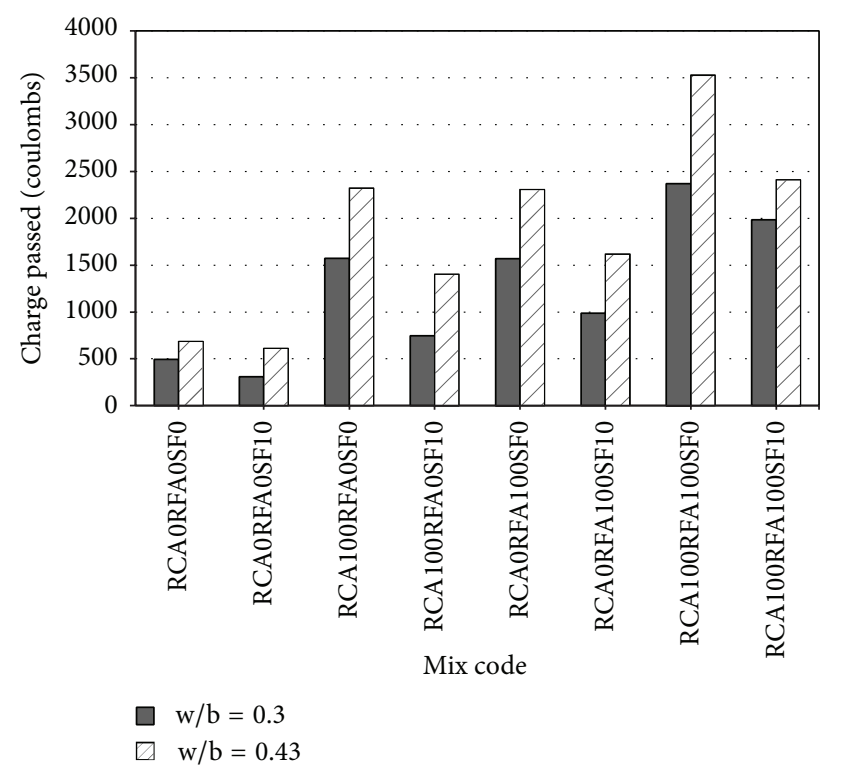

FIGURE 8: RCPT test results of SCCs at 56 days.

with recycled aggregates had a negative effect on all the durability indicators including chloride permeability. Additionally, Safiuddin et al. [25] concluded that the permeable voids of concrete related to chloride penetrated increased with the increase in RAs content.

As expected, relatively higher chloride ion permeability values were calculated for concretes with a high $\mathrm{w} / \mathrm{b}$ ratio compared to those with the low w/b ratio. However, the behavior displayed by the high $\mathrm{w} / \mathrm{b}$ concretes was also seen in the concretes with a low w/b ratio. For control mixes, increasing $\mathrm{w} / \mathrm{b}$ ratio to 0.43 produced an increase in total charge passed through the concrete by the range of 27.9 to $49.5 \%$. The chloride ion permeability of concretes increased with increasing $\mathrm{w} / \mathrm{b}$ ratio, showing a poorer resistance against chloride [8].

The application of SF in concrete mixtures has significantly enhanced the durability properties of the concrete. Test results have generally shown that the use of SF appreciably reduced the chloride ion permeability of concretes. The rate of the reduction appeared to be quite high in the control mixes and RAs concrete. For example, in control mixes, the use of SF decreased the total charge passed by the range of 10.7 to $37.5 \%$. The same trend was observed for the other SCCs series when RAs were used rather than NAs. Although SF makes the ITZ denser, the existence of two ITZs for RAs mixes makes the microstructure of concrete more porous and permeable [35].

In this study, it can be noted that the SCC mixes with recycled aggregates were classified as a low to moderate chloride penetrability, while the control mixes (Series I) were in a very low category of chloride ion resistance according to ASTM C1202 [26].

3.2. Water Sorptivity. Water sorptivity testing is performed to measure the rate of water movement into the concrete specimens under the action of capillary forces. It can be

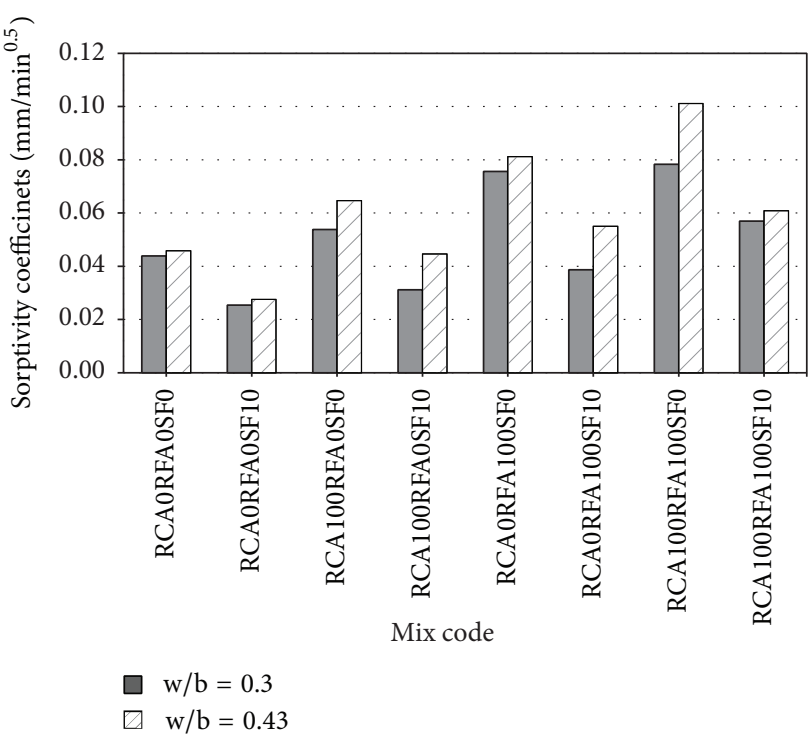

FIGURE 9: Water sorptivity test results at 56 days.

determined from weight gain of the specimen with time of exposure of the lower surface to water [33]. The 56-day sorptivity coefficients of SCC for different aggregate types, $\mathrm{w} / \mathrm{b}$ ratios, and mineral admixtures are given in Table 5 and graphically shown in Figure 9. The test results demonstrated that, when RAs were used, the sorptivity coefficients increased. Generally, the sorptivity test measures the rate at which water is drawn into the pores of concrete. For this, it is strongly related to the absorption capability of aggregate. The highest water absorption of RAs (as coarse and/or fine grade) concrete is a logical consequence of implementation of RAs which has higher water absorption with respect to the NAs. Hence, as RAs were used, a higher rate of water penetration through capillary suction would be expected. As shown in Figure 9, the sorptivity coefficient of RCAs concrete was lower than that for RFAs concrete irrespective of the $w / b$ ratio and SF incorporation. This is due to the increased of the amount of cement paste found on the surfaces of aggregates of smaller sizes, leading to higher values of open porosity. Also, RFAs absorption was higher than that for larger aggregate grade leading to increasing the porosity of concrete. For example, the sorptivity coefficient of mix 0.3 RCA100RFA0SF0 was 0.0538 compared with $0.0756 \mathrm{~mm} / \mathrm{min}^{0.5}$ for $\mathrm{mix}$ 0.3RCA0RFA100SF0. Moreover, the same trend was observed for the other mixes in these series. Using RAs as coarse and/or fine grade remarkably affected the sorptivity behavior of SCCs. The quality of concrete matrix affected the capillarity of concrete by the porosity of RAs. Consequently, increasing mean pore size and total porosity leads to increased capillarity of RAs concrete [16]. Kanellopoulos et al. [27] proposed a direct linear relationship between sorptivity and percentage of open porosity and observed that the increase in the sorptivity was particularly well correlated to the increase in the open porosity. In the present study, utilized RAs as a coarse and fine grade resulted in an increase in sorptivity coefficients by 
TABLE 5: Durability tests results of SCCs at 56 days.

\begin{tabular}{|c|c|c|c|c|c|}
\hline Mix series & Mix code & $\begin{array}{l}\text { Charge passed } \\
\text { (coulombs) }\end{array}$ & $\begin{array}{l}\text { Gas permeability coefficient } \\
\qquad\left(10^{-16} * \mathrm{~m}^{2}\right)\end{array}$ & $\begin{array}{l}\text { Sorptivity coefficient } \\
\left(\mathrm{mm} / \mathrm{min}^{0.5}\right)\end{array}$ & $\begin{array}{c}\text { Water penetration } \\
\text { depth }(\mathrm{mm})\end{array}$ \\
\hline \multirow{4}{*}{ Series I } & 0.3RCA0RFA0SF0 & 494.3 & 1.446 & 0.0439 & 5 \\
\hline & 0.3RCA0RFA0SF10 & 308.7 & 1.047 & 0.0254 & 4 \\
\hline & 0.43RCA0RFA0SF0 & 685.4 & 1.824 & 0.0458 & 10 \\
\hline & 0.43RCA0RFA0SF10 & 612.0 & 1.304 & 0.0275 & 8 \\
\hline \multirow{4}{*}{ Series II } & 0.3RCA100RFA0SF0 & 1574.3 & 2.677 & 0.0538 & 30 \\
\hline & 0.3RCA100RFA0SF10 & 745.6 & 1.987 & 0.0312 & 13 \\
\hline & 0.43RCA100RFA0SF0 & 2323.4 & 3.617 & 0.0647 & 38 \\
\hline & 0.43RCA100RFA0SF10 & 1404.7 & 2.727 & 0.0446 & 25 \\
\hline \multirow{4}{*}{ Series III } & 0.3RCA0RFA100SF0 & 1570.7 & 3.466 & 0.0756 & 35 \\
\hline & 0.3RCA0RFA100SF10 & 989.4 & 2.488 & 0.0387 & 22 \\
\hline & 0.43RCA0RFA100SF0 & 2306.9 & 5.015 & 0.0812 & 40 \\
\hline & 0.43RCA0RFA100SF10 & 1618.4 & 3.747 & 0.055 & 31 \\
\hline \multirow{4}{*}{ Series IV } & 0.3RCA100RFA100SF0 & 2371.1 & 5.817 & 0.0783 & 38 \\
\hline & 0.3RCA100RFA100SF10 & 1982.9 & 4.716 & 0.057 & 25 \\
\hline & 0.43RCA100RFA100SF0 & 3527.8 & 8.827 & 0.1011 & 55 \\
\hline & 0.43RCA100RFA100SF10 & 2412.6 & 6.618 & 0.0609 & 35 \\
\hline
\end{tabular}

the range of 43.9 to $55.4 \%$ compared with the control mixes (Series I).

As seen in Table 5, incorporating SF continuously decreased the sorptivity of SCCs. For control mixes, utilizing SF caused the water sorptivity to drop from 0.044 to 0.025 and from 0.046 to $0.027 \mathrm{~mm} / \mathrm{min}^{0.5}$ at the low and high w/b ratio, respectively. The same trend was observed for other SCCs series. The known beneficial roles of SF in concrete are an increase in strength and a reduction in the capillary absorption of concrete such that SF reduces the sorptivity index of SCCs [36]. In the study of Chan and Ji [37], it was also proved that the utilization of SF replacement by weight of the cement significantly improved the sorptivity of the concretes, particularly for high replacement levels. They attributed their findings to the blockage of capillary and refinement of the pore structure. Reduced sorptivity reflects a finer pore structure that would, for example, inhibit ingress of aggressive elements into the pore system [37]. Therefore, minimizing sorptivity is important in order to reduce the ingress of chloridecontaining or sulfate-containing water into concrete, which can cause serious damage [38].

The enhancement of sorptivity coefficient at 56 days was more pronounced for low w/b mixes as seen in Figure 9. Inasmuch as w/b decreased, the concrete matrix remarkably enhanced and became stronger through decreasing the capillary voids. For mix 0.3RCA100RFA100SF0, sorptivity was lower than that for mix 0.43 RCA100RFA100SF0 by $22.5 \%$. In the same way, decreasing w/b ratio from 0.43 to 0.3 for mix 0.3 RCA100RFA100SF10 reduced the sorptivity coefficient by $6.5 \%$. Özbay [39] reported the same conclusion, finding that increasing the $\mathrm{w} / \mathrm{b}$ ratio from 0.32 to 0.44 enhanced the water sorptivity coefficients of SCCs. Also, Güneyisi et al. [16] reached the same results; that is, sorptivity values increased as $w / b$ increased and concretes with SF exhibited more vulnerability to change in the $\mathrm{w} / \mathrm{b}$ ratio.

3.3. Gas Permeability. The apparent gas permeability calculation was carried out on the basis of the Hagen-Poiseuille relationship for laminar flow of a compressible fluid through a porous body with small capillaries under steady-state conditions [16]. 150, 200, and $300 \mathrm{kPa}$ inlet pressures were used to evaluate the average gas permeability coefficient as recommended by RILEM [28]. Thus, the apparent gas permeability coefficients of SCCs measured at 56 days are presented in Table 5 and depicted in Figure 10.

The lowest gas permeability coefficient at 56 days was quantified at mix 0.3RCA0RFA0SF10 as $1.04 \times 10^{-16} \mathrm{~m}^{2}$. For the control mixes, the ranges of permeability coefficients were found to be $1.04-1.82 \times 10^{-16} \mathrm{~m}^{2}$. For RAs concrete mixes (Series IV), these coefficients were 3-4 times greater than those of control mixes without depending on the w/b ratio and incorporating of SF. Hence, the highest gas permeability coefficient at the end of curing time was recorded at mix 0.43 RCA100RFA100SF0 as $8.82 \times 10^{-16} \mathrm{~m}^{2}$. Furthermore, the gas permeability coefficient of RCAs concrete (Series II) was lower than that of RFAs concrete (Series III) by approximately 1.5 times.

Since the transport properties of concrete strongly depend on its pore structure, the rise in gas permeability of concrete can be attributed to the increased pore structure in concrete due to the RAs addition. Moreover, as mentioned before, the problem associated with the RAs is the new and/or old ITZ that come from residual hydrated cement paste adhered to the surface of the aggregate particle, which leads to more porous and cellular material $[9,35]$. As a result, when 


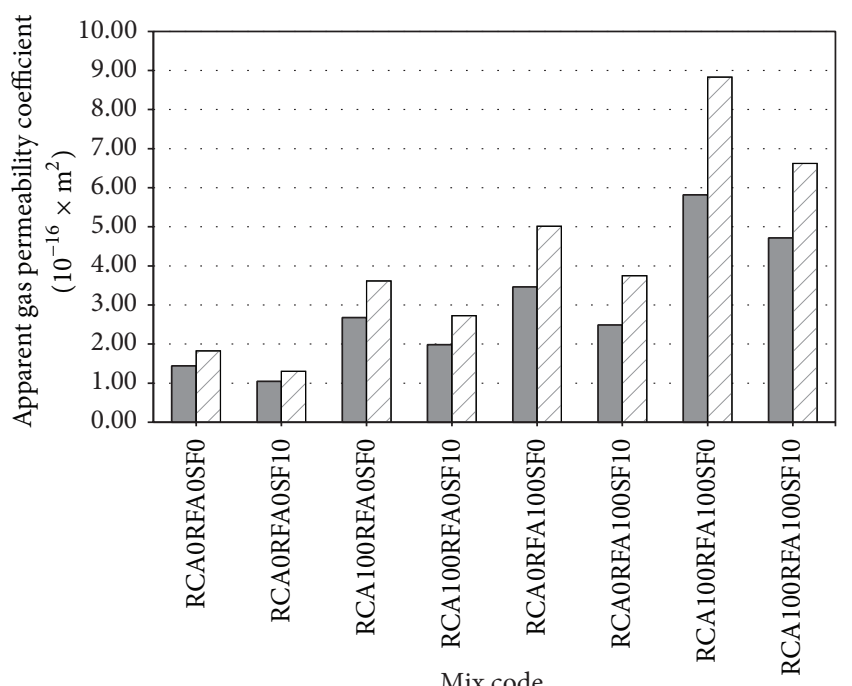

$\mathrm{w} / \mathrm{b}=0.3$

$\mathrm{w} / \mathrm{b}=0.43$

FIGURE 10: Variation of apparent gas permeability coefficients of SCCs at 56 days.

RAs were used, apparent gas permeability value increased regardless of the $\mathrm{w} / \mathrm{b}$ ratio and aggregate grade.

As expected, low $\mathrm{w} / \mathrm{b}$ ratio SCC mixes exhibited a better performance than high $\mathrm{w} / \mathrm{b}$ ratio mixes. In control mixes, for instance, decreasing the $\mathrm{w} / \mathrm{b}$ ratio to 0.3 enhanced the gas permeability coefficient by $24-26 \%$. These findings are compatible with the observations of previous researchers [8, $16,39]$ for the effect of the w/b ratio. The reason is related to the enhancement of the concrete matrix and ITZ due to the decrease in $\mathrm{w} / \mathrm{b}$ ratio through minimizing capillary voids caused by the evaporation of the extra water available inside the concrete. These voids are responsible for the concrete degradation related to the gas diffusion.

In the current study, it was pointed out that the concretes incorporated with SF showed a better performance than concrete with nonexistent SF in terms of gas permeability characteristics. The reduction in gas permeability of concrete can be attributed to the improvement in pore structure of concrete due to the SF addition. Generally, the permeability of concrete reduces by the addition of SF. In this regard, there is a reduction in the water absorption. These effects are the cause of the micropore structure which produces calcium silicate hydrate from the pozzolanic reaction of SF with free lime within the hydration of concrete [40]. It is evident that a high volume of SF modifies the microstructure of the cement paste and such modification will also affect the macropermeability behavior of the concrete. Moreover, the fineness of the SF contributes to providing a better physical improvement through a pore size refinement. Also, the similarity in the variation trends of the apparent gas permeability coefficients of the concretes may be due to the facts mentioned above. In the present study, the refinement of the SCCs had remarkable effect in gas permeability aspect. In control mixes, the gas permeability coefficient decreased by the range of 38.1 to $39.8 \%$ due to

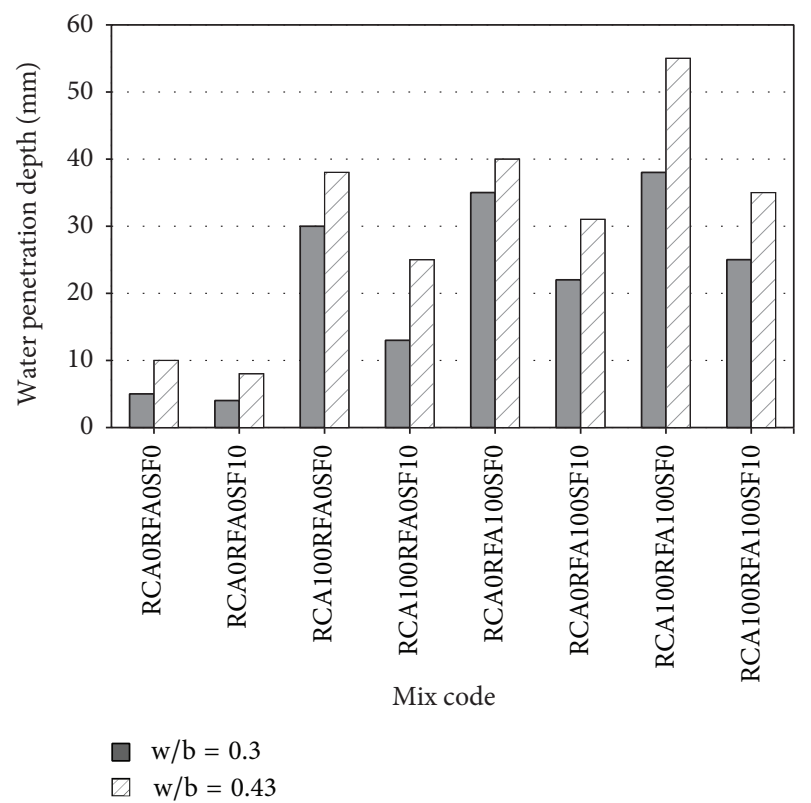

FIGURE 11: Water penetration depths of SCCs at 56 days.

utilizing SF. As shown in Figure 10, the same decreasing trend can be noticed in other SCCs mixes.

3.4. Water Permeability. The variations of water permeability depth of SCCs produced in this study are illustrated in Table 5, also graphically shown in Figure 11. Test results revealed that using RAs made the SCCs more water permeable, irrespective of the size of RAs. Also, it was observed that this effect was more pronounced increasing $\mathrm{w} / \mathrm{b}$ ratio. The highest penetration depth was measured for mix 0.43RCA100RFA100SF0 in Series IV, as $55 \mathrm{~mm}$, whereas the lowest penetration depth was measured for mix 0.3 RCA0RFA0SF10 in Series I, as only $4 \mathrm{~mm}$. The behavior of RAs concrete can be attributed to the porous structure of this aggregate that make water easily penetrate into and through the aggregates under pressure. As a result, water penetrates deeper into the SCCs containing RAs than that of NAs. Furthermore, the increase in porosity can result in an increment of pore connectivity of concrete. As water can penetrate through porous media, the porous RAs may reduce the concrete resistance to water penetration [8]. Also, RAs particles consist of new and old ITZs and the bond between them is weakened, which has led to the formation of higher number of capillaries, thus enabling higher water penetration that might be significant because of the use of unprocessed aggregates [35]. In this study, the adoption of RAs as a coarse and fine grade resulted in a noteworthy increase in the water penetration by 4.5-7.6 times, compared with the control mixes where NAs were used. However, RCAs and RFAs concretes exhibited a comparable performance with control mixes. For instance, at Series II and Series III concretes, water ingress measured at 56 days was deeper by approximately 3-6 and 4-7 times, respectively, compared to the control mixes. 
It was monitored that increasing the $\mathrm{w} / \mathrm{b}$ ratio from 0.3 to 0.43 generally increased the water permeability of concretes. For control mixes, increasing $\mathrm{w} / \mathrm{b}$ ratio increased the depth of water penetration by 2 times. Moreover, in Series IV, water penetration for mix 0.3RCA100RFA100SF0 was $38 \mathrm{~mm}$ compared with $55 \mathrm{~mm}$ for the same mix properties but with higher w/b ratio (0.43RCA100RFA100SF0).

Compared with the mix without SF, a considerable decrease for the length of water permeability of the concrete was observed by utilizing SF for both w/b ratios. The main reason for this decrement is that SF can improve the water impermeability of concrete; hence, SF can take part in the hydration reaction in the early hydration of cement to produce more hydrates and decrease the porosity of concrete composite [34]. In this study, the use of SF provided a marked reduction in the water permeability of SCCs when compared to that of the control concrete. For instant, in control mixes, the reduction in water permeability was $20 \%$ due to incorporating SF. Furthermore, a similar reduction trend was observed for the other SCCs mixes.

The water permeability test may also provide some information about the pore structure of the concrete, the continuity of the pores, and concrete's potential durability against the aggressive media. Generally, concretes exposed to aggressive media are resistant to chemical attacks when their water permeability values are less than $30 \mathrm{~mm}$ [39]. Hence, except Series IV, it can be claimed that all SCCs produced in this study including those with a higher $\mathrm{w} / \mathrm{c}$ ratio are resistant to chemical attacks in aggressive media, especially for mixes containing SF.

3.5. Drying Shrinkage and Weight Loss. Drying shrinkage can be defined as the volumetric change due to the drying of concrete. Firstly, the loss of free water occurs, which causes little to no shrinkage. As the drying of the concrete continues, the adsorbed water is taken away. This adsorbed water is held by hydrostatic tension in the small capillaries $(<50 \mathrm{~nm})$. The loss of this water produces tensile stresses, which cause the concrete to shrink. The shrinkage due to this water loss is significantly larger than that associated with the loss of free water [41]. Drying shrinkage is a long-lasting process that depends on w/c, degree of hydration, curing temperature, relative humidity, duration of drying, aggregate properties, admixture, and cement composition [31, 32, 42]. The typical drying shrinkage versus time curves for SCCs incorporating with RAs are depicted in Figures 12(a), 12(b), 12(c), and 12(d) for NAs (Series I), RCA (Series II), RFA (Series III), and RAs (Series IV) concretes, respectively. Also, the maximum drying shrinkage deformation of SCCs at the end of the 56 days drying period is given in Table 6 .

It can be noted that drying shrinkage rate reduced gradually with the time passed for all mixtures. However, Figure 12 showed that the presence of RAs in concrete led to increasing shrinkage. According to the curves of Series IV, Series III, and Series II, drying shrinkage of concretes containing RCA and/or RFA decreased in this order, but all of the concretes showed higher shrinkage than the control mixtures (Series I). As seen in Figure 12, the lowest shrinkage strains of 315 microstrains at 56 days were measured for
0.3RCA0RFA0SF10 while 0.43RCA100RFA100SF0 had the highest shrinkage value which was found to be 727 microstrains. The high rate of drying shrinkage in RAs concrete should have been connected with the fact that the adhering mortar on the surface of the recycled aggregate, which normally contributes to a considerable absorption of water, could have contributed to the high drying shrinkage. Similar test results were observed by other researchers such that the high absorption as well as the lower modulus of elasticity of RAs was accompanied by the higher shrinkage strain in concrete as verified from the increase in drying shrinkage with increasing volume of RAs in SCCs [34, 42-45]. In addition, SCCs containing RAs were prone to having higher shrinkage strain due to their lower tensile strength with respect to reference mixes. Another factor that may have affected the shrinkage of SCCs is the absorption ability of the RAs. A higher absorption value indicates a higher percent of aggregate voids filled with water, which may lead to an increase in drying shrinkage. Aggregates with high absorption properties are associated with high shrinkage strain in concrete, and this is confirmed by the increase of drying shrinkage with the utilization of RAs and the increase of $\mathrm{w} / \mathrm{b}$ ratio [42]. From the results of the properties of the RAs, the water absorption of the RAs was about four times more than that of NAs; this therefore mostly caused a higher drying shrinkage observed in the concrete containing RAs. However, it is well known that the self-desiccation increases with decreasing $\mathrm{w} / \mathrm{b}$ ratio, and this will cause an increase in the total shrinkage. With increasing the degree of hydration, products of hydrates fill the pore spaces and the amount of movable water decreases; consequently, the amount of drying shrinkage will decrease [46]. For instance, there was an increase in 56-day drying shrinkage by as high as $47 \%, 54 \%, 56 \%$, and $53 \%$ for $0.3 \mathrm{RCA} 100 \mathrm{RFA} 100 \mathrm{SF} 0$, 0.3RCA100RFA100SF10, 0.43RCA100RFA100SF0, and 0.43RCA100RFA100SF10 mixes, respectively, compared to SCCs incorporating NAs (Series I). Moreover, the internal curing effect of RAs as used in SSD condition is to decrease the early age drying shrinkage for SCCs when compared to conventional RAs concretes [12].

It is evident in Figure 12 that the effects of replacing the cement by GGBFS and SF were to reduce the free shrinkage of SCCs remarkably at a low $\mathrm{w} / \mathrm{b}$ ratio. When the shrinkage strains measured at 56 days were considered, the shrinkage of the concrete with ternary use of cement + GGBFS + SF exhibited the highest reduction in comparison to the SCCs without incorporating SF. For instance, drying shrinkage measurement of 0.3 RCA0RFA0SF10 was $24.1 \%$ lower than that of 0.3RCA0RFA0SF0. The test results agreed with the findings of the study conducted by $\mathrm{Li}$ and Yao [18] which showed that the ultrafine mineral admixtures like GGBFS and SF can substantially promote hydration of cement and increase the amount of crystal hydrates and C-S-H gel hydrates in cement paste, which offers a hardened concrete with a stronger structure and higher resistance to deformation caused by applied forces. Moreover, this ultrafine material may fill small pores and voids harmful to the structure of concrete. That might be the mechanism of reducing effect of ultrafine mineral admixtures on drying shrinkage of concrete. Güneyisi et al. 


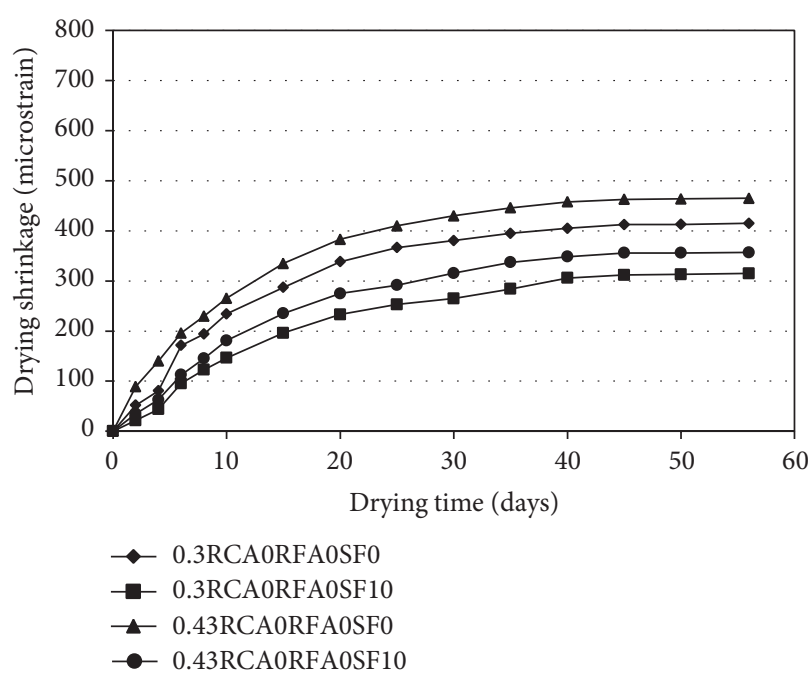

(a)

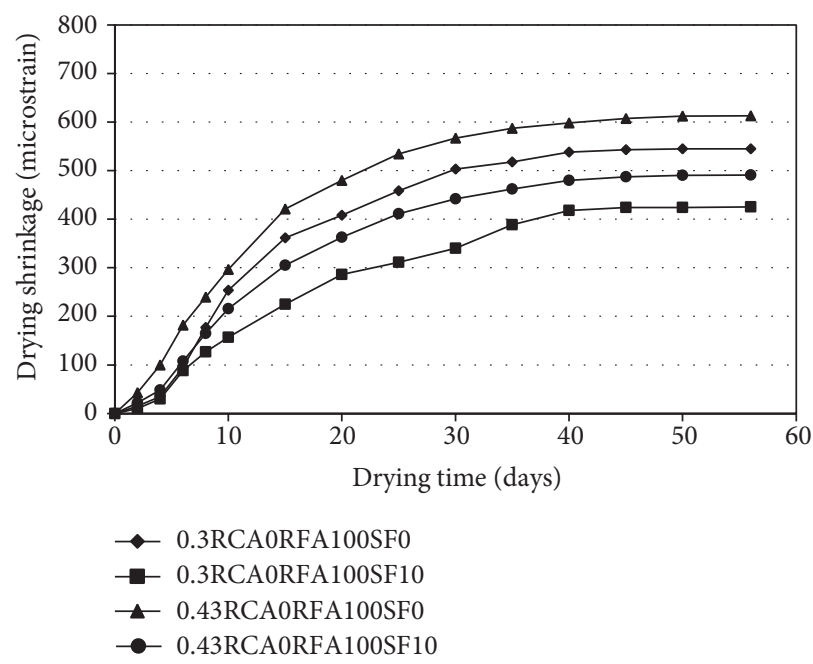

(c)

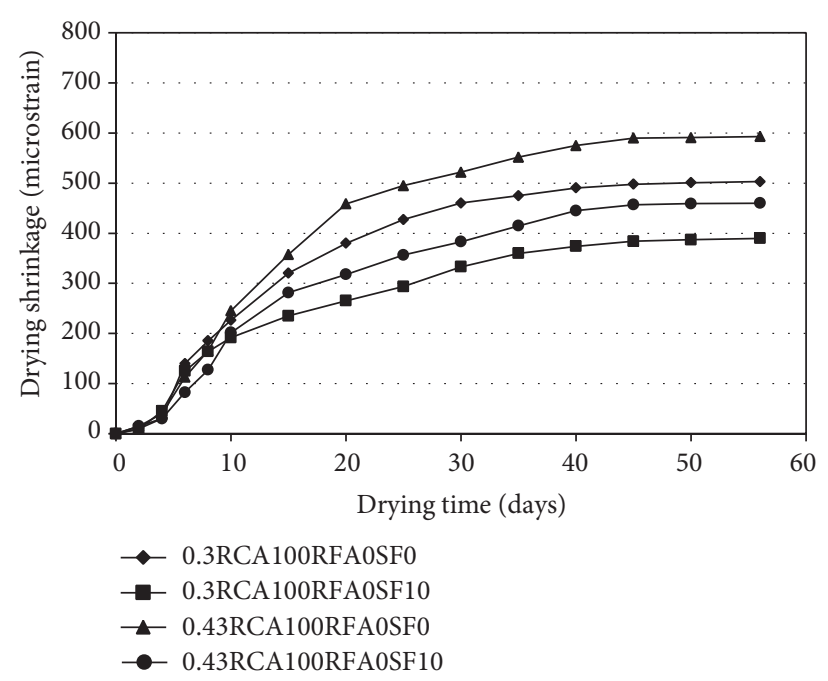

(b)

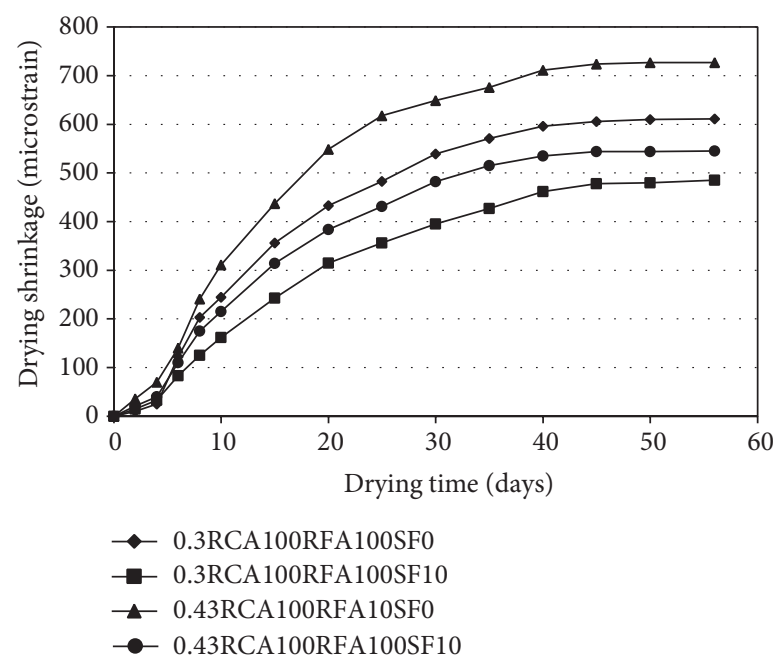

(d)

Figure 12: Drying shrinkage for SCCs according to type of aggregate: (a) NAs (Series I), (b) RCAs (Series II), (c) RFAs (Series III), and (d) RAs (Series IV).

[16] reached the results that SF modified concretes exhibited a lower shrinkage in comparison to the plain concretes. Moreover, the drying shrinkage rates of the concretes had a decreasing tendency with passing drying time, particularly for the SF concretes.

The results of weight loss with time due to the drying for SCCs are shown in Figures 13(a), 13(b), 13(c), and 13(d) for Series I to IV, respectively. Additionally, Table 6 gives the maximum weight loss values of SCCs. Similar to drying shrinkage test results, SCCs incorporated with RAs exhibited a higher weight loss in comparison with the control mixture regardless of the size of RAs. During 56 days of drying period, the difference of weight loss between SCCs mixtures became more distinguishable after one week. The differences were then observed to have an increasing tendency with increasing drying time. However, for the same mix specification, higher amount of RAs as fine and/or coarse grade gave rise to greater water loss inasmuch as the RAs were used in SSD condition, which in turn increased the unit water content. As a result, the increased weight loss led to a higher total drying shrinkage of SCCs.

Replacement of NFAs with RFAs caused an increase in the percentage of weight loss, but this percentage was more obvious when NCAs was replaced by RCAs. For example, a maximum weight loss of 0.43RCA0RFA0SF0 was $63.85 \mathrm{gr}$ compared with 88.3 and 111.15 gr for 0.43 RCA100RFA0SF0 and 0.43RCA0RFA100SF0, respectively. However, for all SCCs mixtures, incorporating SF and/or decreasing the $\mathrm{w} / \mathrm{b}$ ratio resulted in an inhibition in weight loss; for instant, in Series I incorporating SF caused a decrease by $27 \%$ for 0.3RCA0RFA0SF10 compared with 0.3RCA0RFA0SF0 mix. SF decreased the rate of weight loss due to the drying of the concretes. Also, the weight losses were observed to be lower than those of plain concrete [16]. Expectedly, the weight 


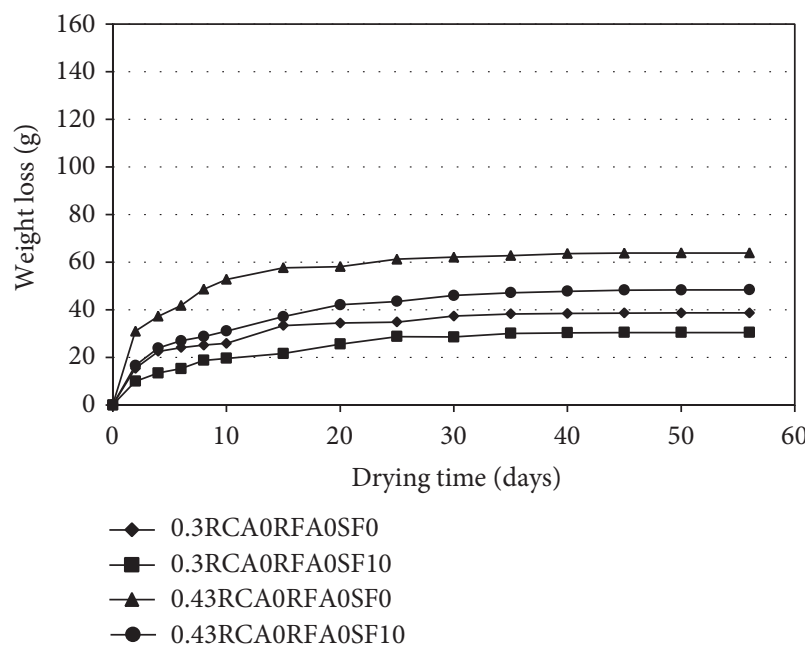

(a)

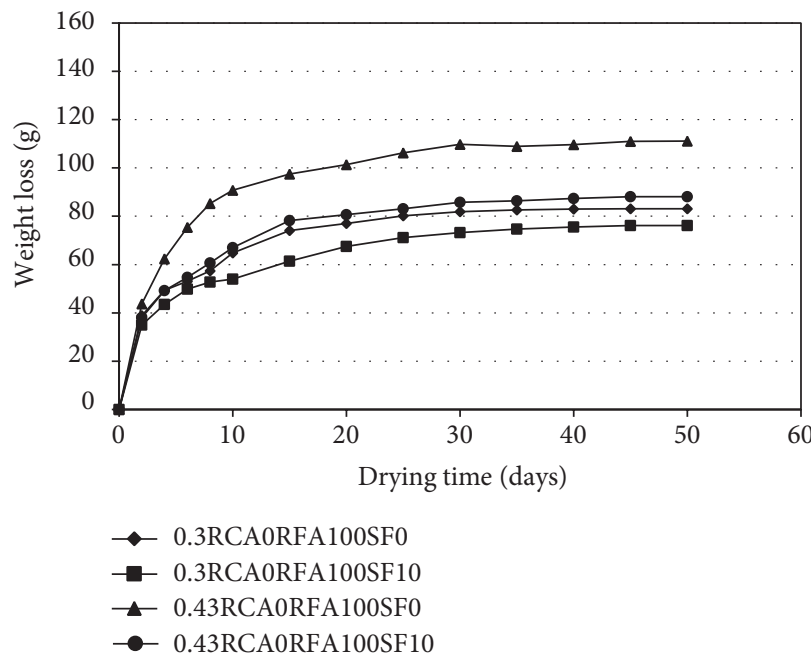

(c)

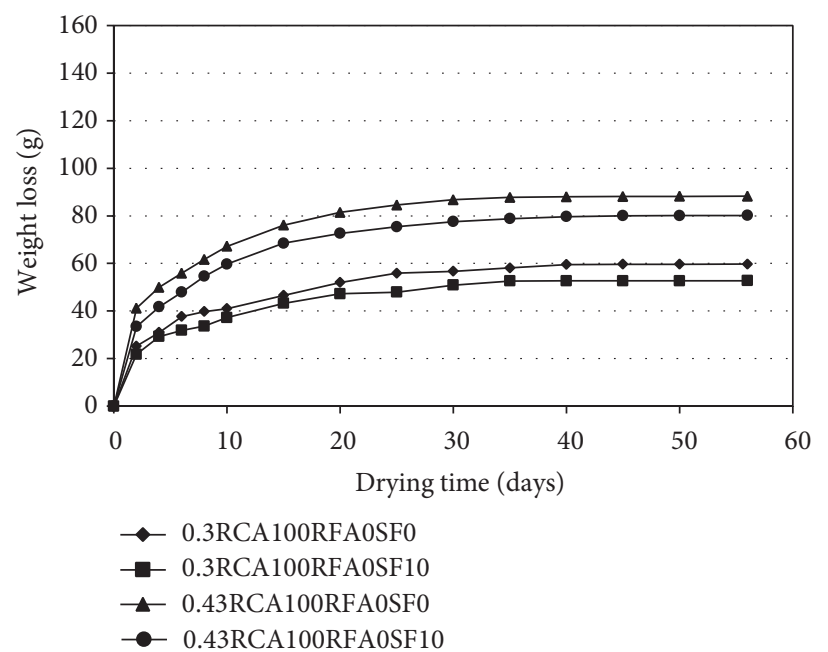

(b)

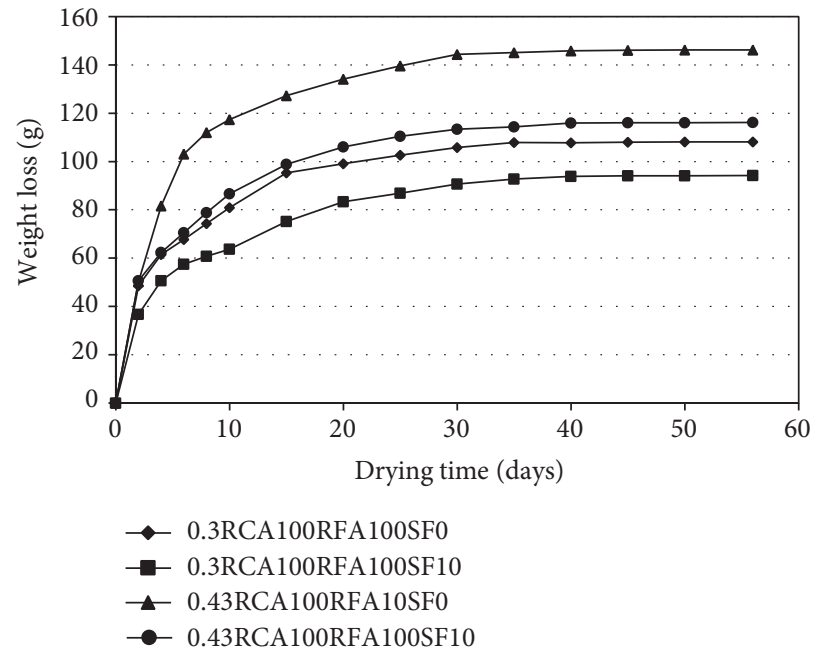

(d)

Figure 13: Weight loss for SCCs according to type of aggregate: (a) NAs (Series I), (b) RCA (Series II), (c) RFA (Series III), and (d) RAs (Series IV).

loss was higher as the w/b ratio increased; for example, 0.43 RCA0RFA0SF0 mix exhibited an increase in weight loss by $65 \%$ relative to the comparable mix with a lower $\mathrm{w} / \mathrm{b}$ ratio (0.3RCA0RFA0SF0). As a result of weight loss measurements of SCCs, it was pointed out that there is no direct relationship between drying shrinkage and weight loss measurement of SCCs. The weight loss parameter alone cannot provide sufficient information on the variation in the drying shrinkage of concretes because drying shrinkage is related to other factors in addition to the weight loss [31, 42].

Figure 14 shows the variation of drying shrinkage with the compressive strength. As seen in the figure, the drying shrinkage decreased whenever compressive strength increased. Moreover, a good correlation between the two parameters can be noticed. The drying shrinkage of all SCCs mixes was within and slightly above the $81 \%$ confidence interval of a linear regression curve.
3.6. Restrained Shrinkage Cracking. Concrete is expected to crack whenever the tensile stress induced by the constraint for the free shrinkage surpasses its tensile strength. The crack developments and the shrinkage cracking age of the restrained shrinkage specimens are shown in Figure 15 while the maximum crack width of SCCs is given in Table 6.

As shown in Figure 15, there was a marked effect of aggregate type on the restrained shrinkage cracking performance of SCCs. For all 16 SCCs mixes, there were small differences for cracking initiate time. It can be seen from Figure 15 that initial cracking of the specimen was observed at the 6th to 10th days for control mixes (Series I); however, the crack initialization of Series IV concrete was observed to occur between the 10th and 13th days. Despite the fact that Series IV mixes had a higher free shrinkage and lower tensile strength, the cracking time extended for approximately 3 to 4 days. RAs were used in SSD condition and this provided water into 
TABLE 6: Drying and restrained shrinkage performance of the SCCs at the end of the 56-day drying period.

\begin{tabular}{|c|c|c|c|c|c|}
\hline Mix series & Mix code & $\begin{array}{c}\text { Drying shrinkage } \\
\text { (microstrain) }\end{array}$ & $\begin{array}{l}\text { Weight loss } \\
\text { (gr) }\end{array}$ & $\begin{array}{c}\text { Average cracking age } \\
\text { (day) }\end{array}$ & $\begin{array}{l}\text { Max crack width } \\
(\mathrm{mm})\end{array}$ \\
\hline \multirow{4}{*}{ Series I } & 0.3RCA0RFA0SF0 & 415 & 38.6 & 7 & 1.40 \\
\hline & 0.3RCA0RFA0SF10 & 315 & 30.4 & 6 & 1.25 \\
\hline & 0.43RCA0RFA0SF0 & 465 & 63.8 & 10 & 1.80 \\
\hline & 0.43RCA0RFA0SF10 & 357 & 48.3 & 8 & 1.70 \\
\hline \multirow{4}{*}{ Series II } & 0.3RCA100RFA0SF0 & 503 & 59.7 & 8 & 1.50 \\
\hline & 0.3RCA100RFA0SF10 & 390 & 52.8 & 7 & 1.30 \\
\hline & 0.43RCA100RFA0SF0 & 593 & 88.30 & 11 & 2.10 \\
\hline & 0.43RCA100RFA0SF10 & 460 & 80.2 & 9 & 1.90 \\
\hline \multirow{4}{*}{ Series III } & 0.3RCA0RFA100SF0 & 546 & 83.2 & 10 & 1.70 \\
\hline & 0.3RCA0RFA100SF10 & 425 & 76.1 & 9 & 1.50 \\
\hline & 0.43RCA0RFA100SF0 & 613.5 & 111.1 & 12 & 2.20 \\
\hline & 0.43RCA0RFA100SF10 & 492 & 88.1 & 11 & 2.00 \\
\hline \multirow{4}{*}{ Series IV } & 0.3RCA100RFA100SF0 & 611 & 108.2 & 11 & 1.80 \\
\hline & 0.3RCA100RFA100SF10 & 485 & 94.2 & 10 & 1.70 \\
\hline & 0.43RCA100RFA100SF0 & 727 & 146.2 & 13 & 2.40 \\
\hline & 0.43RCA100RFA100SF10 & 545 & 116.1 & 12 & 2.20 \\
\hline
\end{tabular}

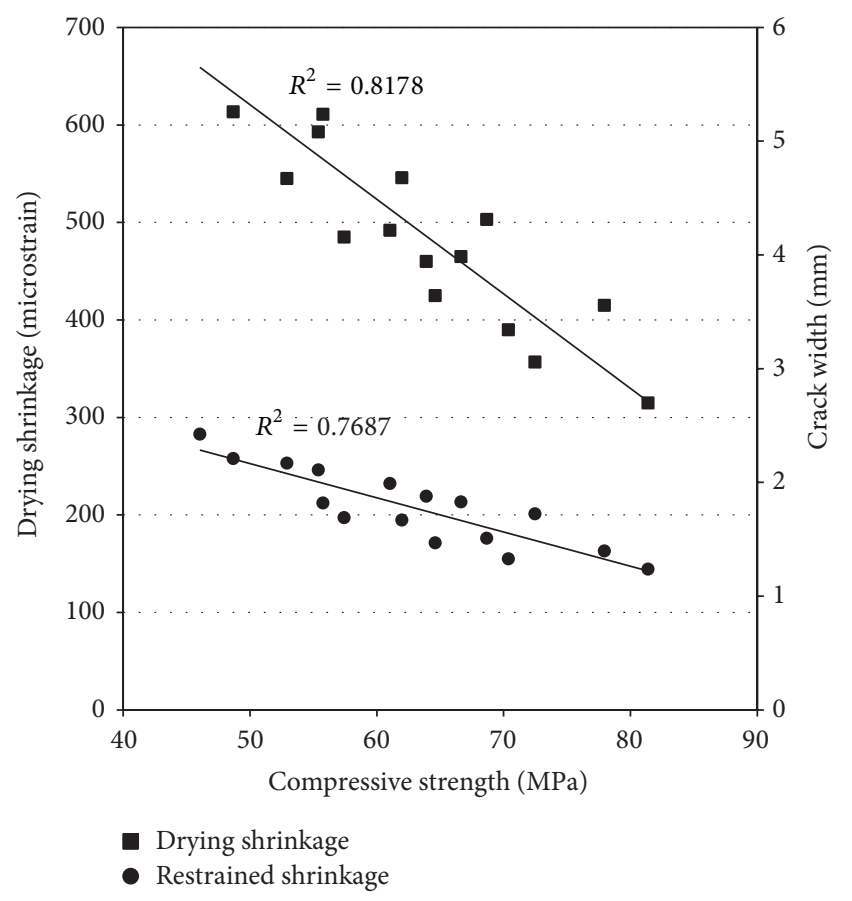

FIGURE 14: Drying and the crack developments of restrained shrinkage specimens within time of SCCs versus with compressive strength.

the drying matrix at the very early ages; thus the cracking time would be extended by reducing the autogenous shrinkage [42]. Water within the prewetted RA is preferred to be drawn from the RA to the surrounding paste because of the larger pore sizes in the RA relative to those in the hydrating cement paste and the emptying of these larger pores produces a much lower capillary stress, which reduces both the measured strain and the propensity for early-age cracking [46, 47]. Furthermore, the lower elastic moduli of SCCs with RAs helped in extending the cracking time with respect to SCCs with NAs.

Though the cracking time extended, the crack opening for SCCs with RAs was faster in the first day due to the weakness of RAs. The lowest crack propagation was observed for 0.3RCA0RFA0SF10 mix as $1.25 \mathrm{~mm}$, irrespective of drying time. The maximum crack width at the end of 56 days was found to be $2.4 \mathrm{~mm}$ for mix 0.43RCA100RFA100SF0 in Series IV. On the other hand, considering the overall drying period, SCCs incorporating RFAs (Series III) exhibited higher crack propagation with respect to Series I and II, respectively. For example, utilizing RAs as a fine grade resulted in a crack width ranging from 1.3 to $2.1 \mathrm{~mm}$ depending on the $\mathrm{w} / \mathrm{b}$ ratio and incorporating of SF while these values increased to the range of 1.7 to $2.4 \mathrm{~mm}$ for fine and coarse grade (Series IV). The increment observed in the cracking width for SCCs with RAs mostly resulted from the increase in free shrinkage and the decrease in both tensile strength and modulus of elasticity. However, in the present study, restrained shrinkage of SCCs was also affected by the paste parameters like $\mathrm{w} / \mathrm{b}$ ratio and microfine particles incorporated like SF. For instance, increasing the w/b ratio from 0.3 to 0.43 caused an increase in the restrained shrinkage crack width values by $28.5 \%$ for 0.3RCA0RFA0SF0 compared with 0.43RCA0RFA0SF0 mix. On the other hand, the incorporation of SF decreased the width of restrained shrinkage crack values by about $12 \%$ for 0.3RCA0RFA0SF0 compared with 0.3RCA0RFA0SF10. The trend of crack width decrement was valid for other SCCs mixes. The final crack widths of SF concretes were less than those of control concrete [16].

As shown in Figure 14, irrespective of the aggregate type, $\mathrm{w} / \mathrm{b}$ ratio, and incorporation or not of SF, the crack due to 


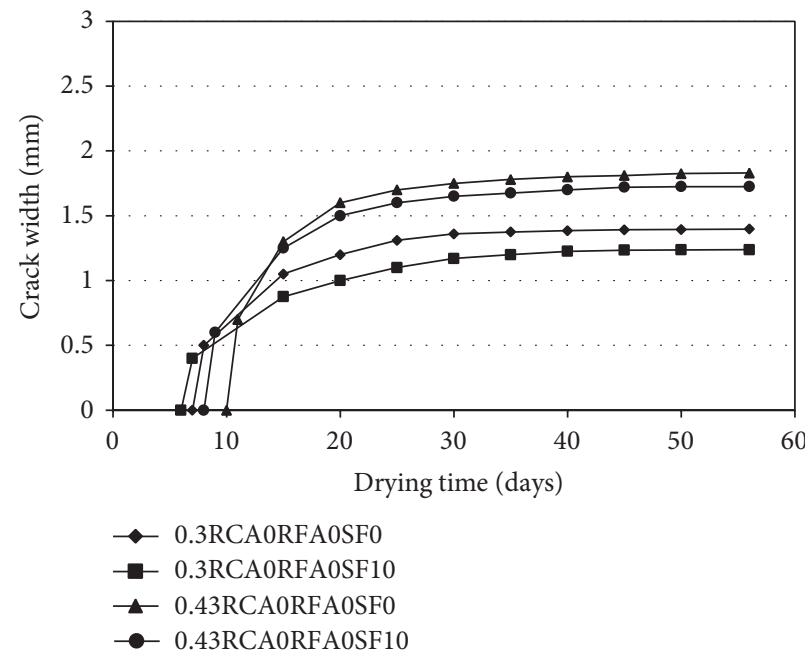

(a)

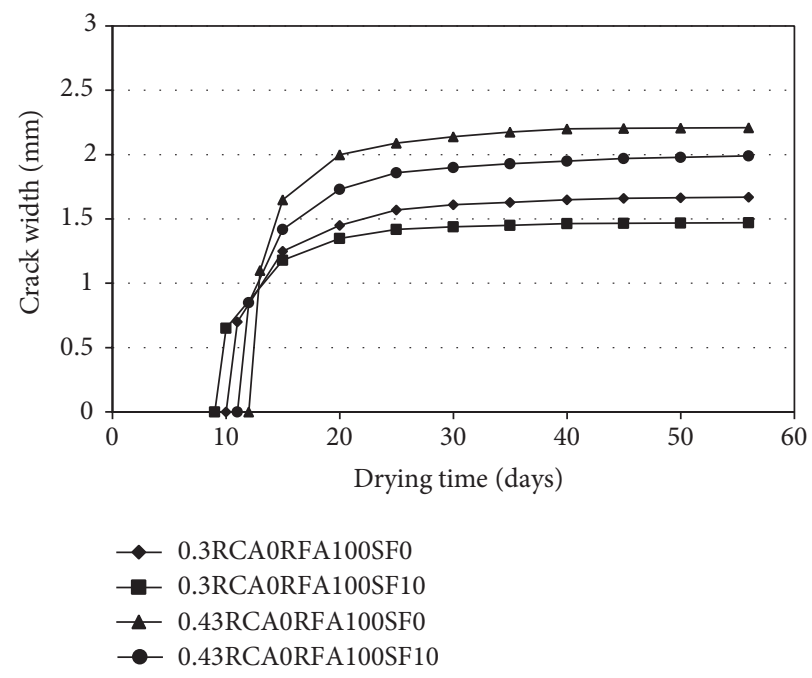

(c)

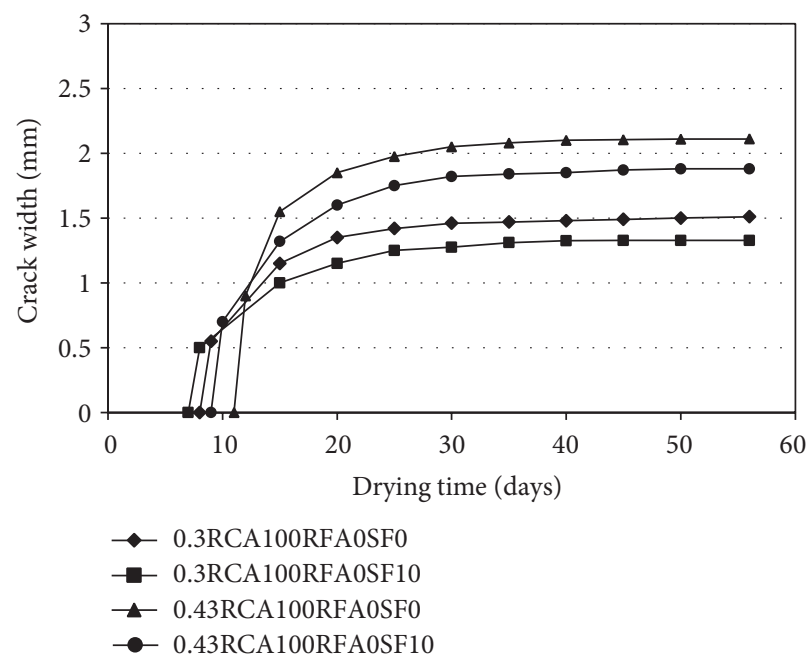

(b)

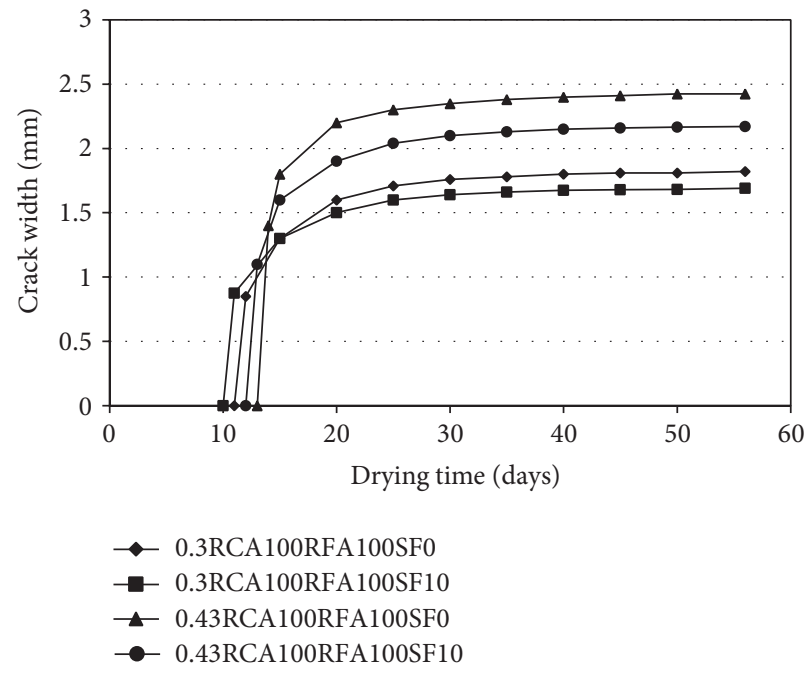

(d)

FIGURE 15: Restrained shrinkage for SCCs according to type of aggregate: (a) NAs (Series I), (b) RCA (Series II), (c) RFA (Series III), and (d) RAs (Series IV).

restrained shrinkage of SCCs exhibited a good linear correlation (approximately $77 \%$ regression factor) with compressive strength as for drying shrinkage.

\section{Conclusions}

The following conclusions were drawn from the results of this experimental study.

(i) Due to the high permeable and porous structure, incorporating RCA and/or RFA resulted in a systematic increase in chloride-ion permeability for SCCs. Compared to Series III mixes, Series II mixes seemed to be more resistant to chloride ingress. Moreover, test results showed that the negative effect of RAs on the chloride ion permeability remarkably diminished with the decrease of $w / b$ ratio and incorporating SF.

(ii) SCC incorporating RCAs and/or RFAs revealed a systematic increase in sorptivity coefficient values.
Increasing mean pore size and total porosity increased capillarity of RAs concrete.

(iii) The highest gas permeability coefficient for SCCs was obtained at mix 0.43RCA100RFA100SF0 as $8.82 \times$ $10^{-16} \mathrm{~m}^{2}$. Since the transport properties of concretes are strongly depending on their pore structure, the raising of gas permeability of concrete can be attributed to the increased pore structure in concrete due to RAs addition.

(iv) The lowest water penetration depth was measured for 0.3RCA0RFA0SF10 as $4 \mathrm{~mm}$ whereas the highest penetration depth was measured for 0.43RCA100RFA100SF0 as $55 \mathrm{~mm}$ at 56 days. Except for Series IV, it can be claimed that all SCCs produced in this study for both $\mathrm{w} / \mathrm{b}$ ratios are resistant to chemical attacks in aggressive media, especially for mixes containing SF. 
(v) For all SCCs mixes tested in this study, drying shrinkage rate reduced gradually with the time passed. Furthermore, the drying shrinkage of SCCs with RAs was much higher than that of concrete with NAs.

(vi) Similar to drying shrinkage test results, SCCs incorporating RAs exhibited higher weight loss in comparison with the control mixture. However, for the same mix specification, higher amount of RAs as fine and/or coarse grade resulted in a greater water loss inasmuch as the RAs were used in SSD condition, which in turn increased the unit water content.

(vii) The cracking time extended by reducing the autogenous shrinkage because RAs was used in SSD condition and this provided water into the drying matrix at the very early ages. Furthermore, the lower elastic moduli of SCCs with RAs helped in extending the cracking time with respect to SCCs with NAs.

(viii) For all SCCs mixtures, incorporating SF and/or decreasing the $\mathrm{w} / \mathrm{b}$ ratio resulted in a better performance related to drying shrinkage, weight loss, and final restrained shrinkage cracking width.

\section{Conflict of Interests}

The authors declare that there is no conflict of interests regarding the publication of this paper.

\section{References}

[1] E. P. Koehler and D. W. Fowler, Aggregates in Self-Consolidating Concrete. Final Report ICAR Project 108: Aggregates in SelfConsolidating Concrete, International Center for Aggregates Research (ICAR), 2007.

[2] Z. J. Grdic, G. A. Toplicic-Curcic, I. M. Despotovic, and N. S. Ristic, "Properties of self-compacting concrete prepared with coarse recycled concrete aggregate," Construction and Building Materials, vol. 24, no. 7, pp. 1129-1133, 2010.

[3] K. C. Panda and P. K. Bal, "Properties of self compacting concrete using recycled coarse aggregate," Procedia Engineering, vol. 51, pp. 159-164, 2013.

[4] EFNARC, European Guidelines for Self-Compacting Concrete, Specification and Production and Use, Association House, London, UK, 2005.

[5] M. Gesoğlu, E. Güneyisi, and H. Ö. Öz, "Properties of lightweight aggregates produced with cold-bonding pelletization of fly ash and ground granulated blast furnace slag," Materials and Structures, vol. 45, no. 10, pp. 1535-1546, 2012.

[6] M. D. Safiuddin, M. A. Salam, and M. Z. Jumaat, "Effects of recycled concrete aggregate on the fresh properties of selfconsolidating concrete," Archives of Civil and Mechanical Engineering, vol. 11, no. 4, pp. 1023-1041, 2011.

[7] S. C. Kou and C. S. Poon, "Properties of self-compacting concrete prepared with coarse and fine recycled concrete aggregates," Cement and Concrete Composites, vol. 31, no. 9, pp. 622627, 2009.

[8] E. Güneyisi, M. Gesoğlu, Z. Algin, and H. Yazici, "Effect of surface treatment methods on the properties of self-compacting concrete with recycled aggregates," Construction and Building Materials, vol. 64, pp. 172-183, 2014.
[9] T. C. Hansen, "Physical structure of hardened cement paste. A classical approach," Materials and Structures, vol. 19, no. 6, pp. 423-436, 1986.

[10] A. Katz, "Properties of concrete made with recycled aggregate from partially hydrated old concrete," Cement and Concrete Research, vol. 33, no. 5, pp. 703-711, 2003.

[11] R. K. Dhir, M. C. Limbachiya, and T. Leelawat, "Suitability of recycled concrete aggregate for use in BS 5328 designated mixes," Proceedings of the Institution of Civil Engineers, vol. 134, no. 3, pp. 257-274, 1999.

[12] M. Salau, E. Ikponmwosa, and A. Adeyemo, "Shrinkage deformation of concrete containing recycled coarse aggregate," British Journal of Applied Science \& Technology, vol. 4, no. 12, pp. 1791-1807, 2014.

[13] J. M. Soberón, "Shrinkage of concrete with replacement of aggregate with recycled concrete aggregate," in Proceedings of the 5th ACI International Conference on Innovations in Design with Emphasis on Seismic, Wind and Environmental Loading; Quality Control and Innovations in Materials/Hot-Weather Concreting, pp. 475-495, Cancún, Mexico, 2002.

[14] H. Matsushita and C. T. Tsuruta, "Experimental studies on compressive strength and drying shrinkage of recycled aggregate concrete," in Proceedings of the International Seminar on Recycled Concrete, pp. 69-78, Niigata University and Japan Concrete Institute (JCI), 2000.

[15] T. Yamato, M. Soeda, and Y. Emoto, "Physical properties of recycled aggregate and the utilization as concrete aggregate," in Proceedings of the International Seminar on Recycled Concrete, pp. 59-68, Niigata University, Japan Concrete Institute, 2000.

[16] E. Güneyisi, M. Gesoğlu, S. Karaoğlu, and K. Mermerdaş, "Strength, permeability and shrinkage cracking of silica fume and metakaolin concretes," Construction and Building Materials, vol. 34, pp. 120-130, 2012.

[17] W. A. Al-Khaja, "Strength and time-dependent deformations of silica fume concrete for use in Bahrain," Construction and Building Materials, vol. 8, no. 3, pp. 169-172, 1994.

[18] J. Li and Y. Yao, "A study on creep and drying shrinkage of high performance concrete," Cement and Concrete Research, vol. 31, no. 8, pp. 1203-1206, 2001.

[19] Turkish Standards, "Cement-part 1: composition, specifications and conformity criteria for common cements," TS EN 197-1, 2002.

[20] ITS, “Aggregates for concrete," Tech. Rep. TS 706 EN 12620-A1, Institute of Turkish Standards, Ankara, Turkey, 2009.

[21] ASTM International, ASTM C 127. Standard Test Method for Specific Gravity and Absorption of Coarse Aggregate, Annual Book of ASTM Standards, ASTM International, West Conshohocken, Pa, USA, 2007.

[22] ASTM, "Standard practice for making and curing concrete test specimens in the laboratory," ASTM C 192, Annual Book of ASTM Standards, 2007.

[23] E. Güneyisi, M. Gesoğlu, and E. Booya, "Fresh properties of selfcompacting cold bonded fly ash lightweight aggregate concrete with different mineral admixtures," Materials and Structures, vol. 45, pp. 1849-1859, 2012.

[24] V. Corinaldesi and G. Moriconi, "Influence of mineral additions on the performance of $100 \%$ recycled aggregate concrete," Construction and Building Materials, vol. 23, no. 8, pp. 28692876, 2009.

[25] M. Safiuddin, U. J. Alengaram, M. A. Salam, M. Z. Jumaat, F. F. Jaafar, and H. B. Saad, "Properties of high-workability concrete 
with recycled concrete aggregate," Materials Research, vol. 14, no. 2, pp. 248-255, 2011.

[26] ASTM, "Standard test method for electrical indication of concrete's ability to resist chloride ion penetration," ASTM C1202, 2009.

[27] A. Kanellopoulos, D. Nicolaides, and M. F. Petrou, "Mechanical and durability properties of concretes containing recycled lime powder and recycled aggregates," Construction and Building Materials, vol. 53, pp. 253-259, 2014.

[28] RILEM, “TC 116-PCD. Permeability of concrete as a criterion of its durability," Materials and Structures, vol. 32, pp. 174-179, 1999.

[29] Institute of Turkish Standards Testing, "Hardened concrete-part 8: depth of penetration of water under pressure," TS EN 12390-8, Institute of Turkish Standards Testing, Ankara, Turkey, 2002.

[30] ASTM International, ASTM C157, Standard Test Method for Length Change of Hardened Hydraulic-Cement Mortar and Concrete, Annual Book of ASTM Standards, ASTM International, West Conshohocken, Pa, USA, 2007.

[31] K. Wiegrink, S. Marikunte, and S. P. Shah, "Shrinkage cracking of high-strength concrete," ACI Materials Journal, vol. 93, no. 5, pp. 409-415, 1996.

[32] S. P. Shah, M. E. Karaguler, and M. Sarigaphuti, "Effects of shrinkage-reducing admixtures on restrained shrinkage cracking of concrete," ACI Materials Journal, vol. 89, no. 3, pp. 289295, 1992.

[33] P. Suvash and Z. Gideon, "Mechanical and durability properties of recycled concrete aggregate for normal strength structural concrete," International Journal of Sustainable Construction Engineering \& Technology, vol. 4, no. 1, pp. 89-103, 2013.

[34] M.-H. Zhang, L. Li, and P. Paramasivam, "Shrinkage of highstrength lightweight aggregate concrete exposed to dry environment," ACI Materials Journal, vol. 102, no. 2, pp. 86-92, 2005.

[35] C. Sumanth, K. Ratna, and P. Rathish, "Mechanical and durability properties of self-compacting concrete with recycled concrete aggregates," International Journal of Scientific \& Engineering Research, vol. 4, no. 5, pp. 260-264, 2013.

[36] C. Tasdemir, M. A. Tasdemir, N. Mills, B. I. G. Barr, and F. D. Lydon, "Combined effects of silica fume, aggregate type, and size on postpeak response of concrete in bending," ACI Materials Journal, vol. 96, no. 1, pp. 74-83, 1999.

[37] S. Y. N. Chan and X. Ji, "Water sorptivity and chloride diffusivity of oil shale ash concrete," Construction and Building Materials, vol. 12, no. 4, pp. 177-183, 1998.

[38] P. Chindaprasirt, C. Chotithanorm, H. T. Cao, and V. Sirivivatnanon, "Influence of fly ash fineness on the chloride penetration of concrete," Construction and Building Materials, vol. 21, no. 2, pp. 356-361, 2007.

[39] E. Özbay, Effects of mineral admixtures on the fresh and hardened properties of self compacting concretes: binary, ternary and quaternary systems [Ph.D. thesis], 2007.

[40] F. Wang and S. Li, "Effect of silica fume on workability and water impermeability of concrete," Applied Mechanics and Materials, vol. 238, pp. 157-160, 2012.

[41] A. Neville, Concrete Neville's Insights and Issues, Thomas Telford Publishing, 2006.

[42] M. Gesoğlu, T. Özturan, and E. Güneyisi, "Shrinkage cracking of lightweight concrete made with cold-bonded fly ash aggregates," Cement and Concrete Research, vol. 34, no. 7, pp. 1121-1130, 2004.

[43] O. Kayali, M. N. Haque, and B. Zhu, "Drying shrinkage of fibrereinforced lightweight aggregate concrete containing fly ash,"
Cement and Concrete Research, vol. 29, no. 11, pp. 1835-1840, 1999.

[44] S. P. Shah, M. E. Karaguler, and M. Sarigaphuti, "Effects of shrinkage-reducing admixtures on restrained shrinkage cracking of concrete," ACI Materials Journal, vol. 89, no. 3, pp. 289295, 1992.

[45] A. M. Neville and J. J. Brooks, Concrete Technology, Longman Scientific and Technical, Essex, UK, 1987.

[46] D. Bentz and W. Weiss, "Internal curing: a 2010 state-of-theart review," NISTIR 7765, National Institute of Standards and Technology, 2011.

[47] D. P. Bentz, "Influence of internal curing using lightweight aggregates on interfacial transition zone percolation and chloride ingress in mortars," Cement and Concrete Composites, vol. 31, no. 5, pp. 285-289, 2009. 

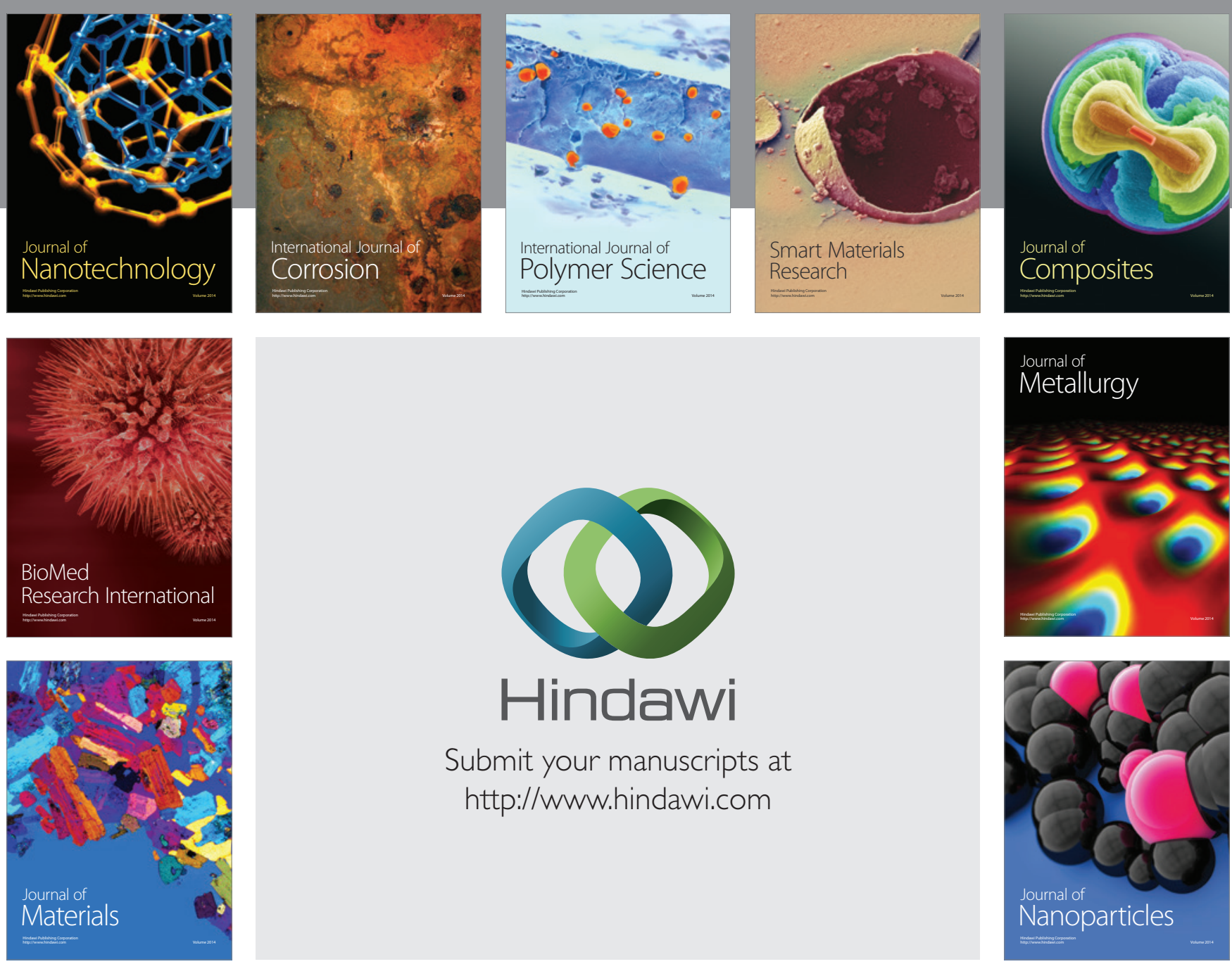

Submit your manuscripts at http://www.hindawi.com
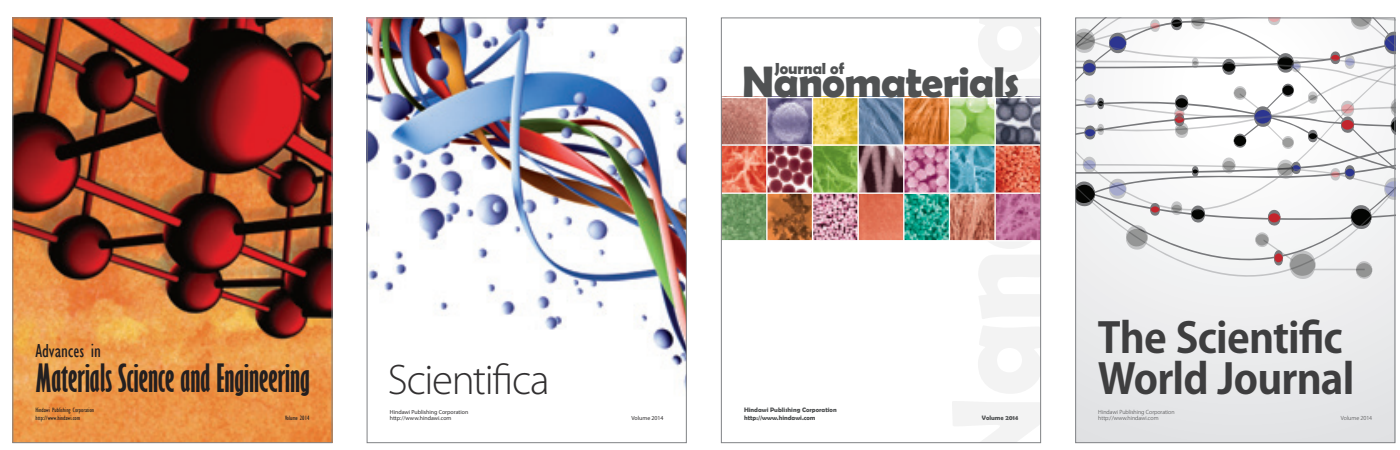

\section{The Scientific World Journal}
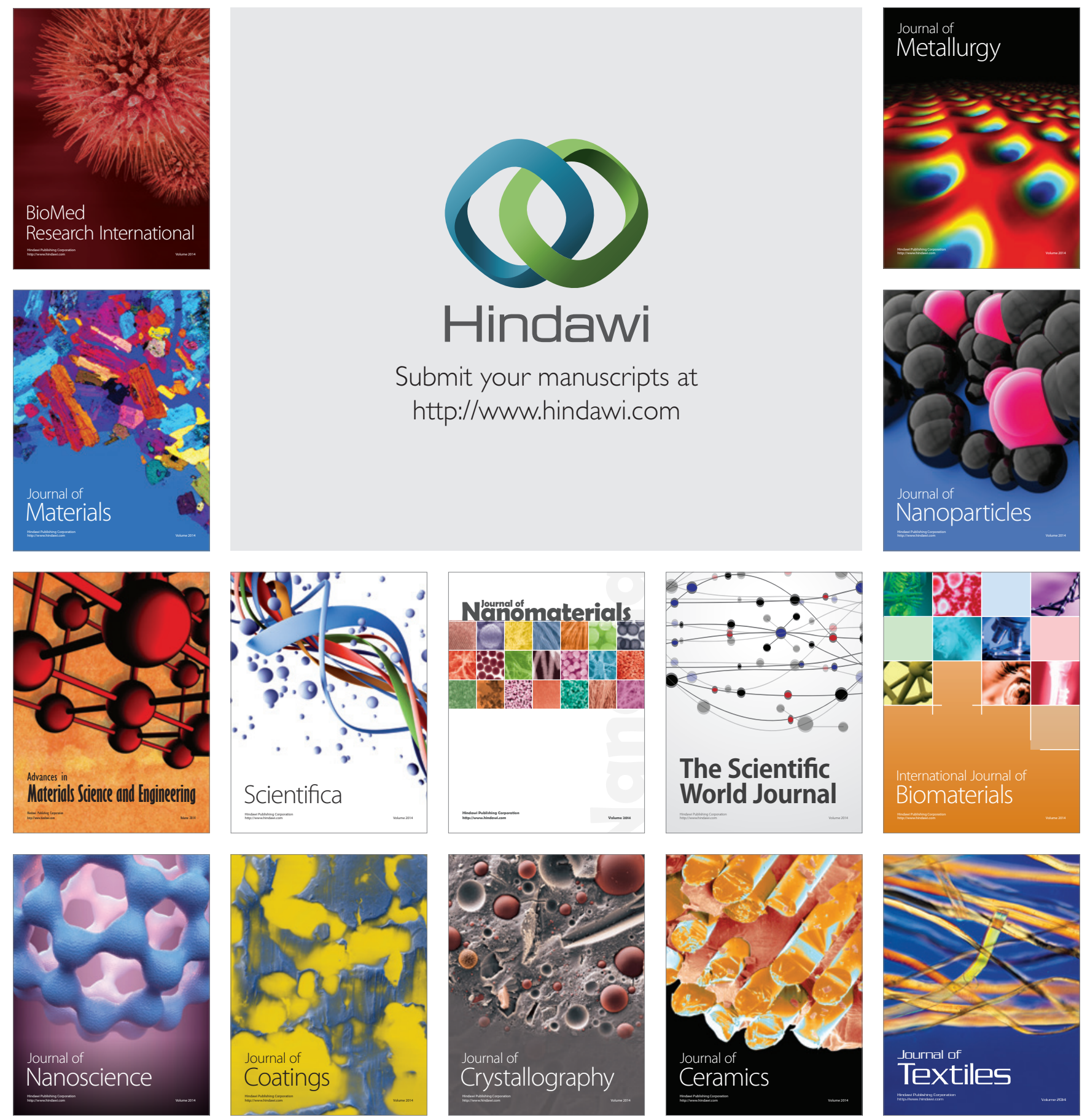